\title{
Fatty acid amide hydrolase is a key regulator of the endocannabinoid-induced myocardial tissue injury
}

\author{
Partha Mukhopadhyay ${ }^{1,}{ }^{*}$, Bèla Horváth ${ }^{1,}{ }^{*}$, Mohanraj Rajesh ${ }^{1}$, Shingo Matsumoto ${ }^{2}$, Keita \\ Saito $^{2}$, Sándor Bátkai ${ }^{1}$, Vivek Patel ${ }^{1}$, Galin Tanchian ${ }^{1}$, Rachel Y Gao ${ }^{1}$, Benjamin F. \\ Cravatt $^{3}$, György Haskó ${ }^{4}$, and Pál Pacher ${ }^{1}$ \\ ${ }^{1}$ Laboratory of Physiologic Studies, National Institute on Alcohol Abuse and Alcoholism, National \\ Institutes of Health, Bethesda, Maryland, USA \\ 2 Radiation Biology Branch, $\mathrm{NCl}$, National Institutes of Health, Bethesda, Maryland, USA \\ ${ }^{3}$ The Skaggs Institute for Chemical Biology and Department of Cell Biology, The Scripps \\ Research Institute, La Jolla, California \\ ${ }^{4}$ Department of Surgery, University of Medicine and Dentistry of New Jersey-New Jersey Medical \\ School, Newark, New Jersey 07103, USA
}

\begin{abstract}
Previous studies have suggested that increased levels of endocannabinoids in various cardiovascular disorders (e.g. different forms of shock, cardiomyopathies, atherosclerosis) through the activation of $\mathrm{CB}_{1}$ cannabinoid receptors may promote cardiovascular dysfunction and tissue injury. We have investigated the role of the main endocannabinoid anandamide metabolizing enzyme (fatty acid amide hydrolase; FAAH) in the myocardial injury induced by an important chemotherapeutic drug doxorubicin (DOX; known for its cardiotoxicity mediated by increased reactive oxygen and nitrogen species generation) using well-established acute and chronic cardiomyopathy models in mice. The DOX-induced myocardial oxidative/nitrative stress (increased 4-hydroxynonenal(HNE), protein carbonyl, nitrotyrosine levels, decreased glutathione content) correlated with multiple cell death markers, which were enhanced in FAAH knockout mice exhibiting significantly increased DOX-induced mortality and cardiac dysfunction compared to their wild types. The effects of DOX in FAAH knockouts were attenuated by $\mathrm{CB}_{1}$ receptor antagonists. Furthermore, anandamide induced enhanced cell death in human cardiomyocytes pretreated by FAAH inhibitor, and enhanced sensitivity to ROS generation in inflammatory cells of FAAH knockouts. These results suggest that in pathological conditions associated with acute oxidative/nitrative stress FAAH plays a key role in controlling the tissue injury, which is, at least in part, mediated by the activation of $\mathrm{CB}_{1}$ receptors by endocannabinoids.
\end{abstract}

Corresponding Author: Pál Pacher M.D., Ph.D., F.A.P.S., F.A.H.A., Section on Oxidative Stress Tissue Injury, Laboratory of Physiological Studies, National Institutes of Health/NIAAA, 5625 Fishers Lane, MSC-9413, Bethesda, Maryland 20892-9413, USA., Phone: (301)443-4830; Fax: (301)480-0257; pacher@mail.nih.gov.

*equally contributed

Disclosures: No conflict of interest to disclose.

Dr. Pacher dedicates this study to his beloved mother Iren Bolfert who died from the cardiovascular complications of chemotherapy.

Publisher's Disclaimer: This is a PDF file of an unedited manuscript that has been accepted for publication. As a service to our customers we are providing this early version of the manuscript. The manuscript will undergo copyediting, typesetting, and review of the resulting proof before it is published in its final citable form. Please note that during the production process errors may be discovered which could affect the content, and all legal disclaimers that apply to the journal pertain. 


\section{Introduction}

Endocannabinoids are part of a novel bioactive lipid signaling system both in the central nervous system as well as in various peripheral organs [1,2]. Increasing recent evidence implicates dysregulation of the endocannabinoid system in the pathogenesis of various cardiovascular diseases, ranging from myocardial infarction, shock, and cardiomyopathy/ heart failure to cardiovascular complications of liver cirrhosis and atherosclerosis [3]. These preclinical reports demonstrated increased plasma, circulating inflammatory cell, and/or myocardial endocannabinoid levels in these pathologies, and implicated activation of cannabinoid- $1\left(\mathrm{CB}_{1}\right)$ receptor by endocannabinoids in the pathogenesis of cardiovascular dysfunction and/or disease progression [4,5]. In these studies, $\mathrm{CB}_{1}$ antagonists improved the hemodynamic alterations $[2,5]$. Furthermore, $\mathrm{CB}_{1}$ receptor activation by endocannabinoid anandamide or synthetic ligands in primary human endothelial cells [6], cardiomyocytes [7] and macrophages [8] promotes increased reactive oxygen species (ROS) generation and cell death, thereby contributing to tissue injury. In models of atherosclerosis pharmacological inhibition or genetic deletion of $\mathrm{CB}_{1}$ attenuates the vascular inflammation and interrelated disease progression, and also decreases smooth muscle proliferation [9-11].

In contrast, activation of $\mathrm{CB}_{2}$ receptors by endocannabinoids or synthetic ligands on inflammatory cells may limit the inflammatory response and ROS generation by reducing migration and/or activation of these cells in various models [3,12-14]. Dysregulation of the endocannabinoid system (e.g. tonic activation of $\mathrm{CB}_{1}$ receptors by endocannabinoids) has also been implicated in the development of various cardiovascular risk factors in obesity/ metabolic syndrome and diabetes (e.g. plasma lipid alterations, hepatic steatosis, abdominal obesity, inflammation, etc.) in humans $[4,15,16]$.

Fatty acid amide hydrolase (FAAH), the enzyme responsible for the degradation of the main endocannabinoid anandamide and related fatty acid amides in vivo [17], has emerged as a target for modulating endocannabinoid signaling [18], with a therapeutic potential in anxiety, pain, and various inflammatory disorders [19,20]. However, genetic deletion or pharmacological inhibition of FAAH may also promote ROS generation and liver injury under pathological condition [21].

In this study using genetic deletion of FAAH, we aimed to explore the role of this key endocannabinoid metabolizing enzyme, in the development of myocardial injury induced by an important chemotherapeutic drug doxorubicin (DOX) known for its cardiotoxicity mediated by increased reactive and nitrogen species generation [22-25] utilizing wellestablished acute and chronic cardiomyopathy models in mice [7,24,26-30], in which increased myocardial endocannabinoid levels and $\mathrm{CB}_{1}$ receptors were implicated in the development of cardiac dysfunction [7,28].

\section{Materials and methods}

\section{Animals/drugs}

Protocols involving the use of animals were approved by the Institutional Animal Care and Use Committees and were performed in line with the National Institutes of Health (NIH) guidelines for the care and use of laboratory animals. FAAH knockout (FAAH-/-) mice were backcrossed into the C57BL/6J background as previously described $[19,31]$. The FAAH-/- or wild type (FAAH+/+) mice were generated from double-heterozygous breeding pairs and were genotyped (Transnetyx, Cordova, TN) at 4-5weeks. 7-11 weeks old male FAAH+/+ and FAAH-/- mice were acutely administered with single high dose (20 $\mathrm{mg} / \mathrm{kg}$ ) of DOX-HCl (termed aDOX; Sigma Chemicals, St. Louis, Missouri) intraperitoneally (I.P.). Treatment with the $\mathrm{CB}_{1}$ antagonists AM281 (Tocris, MI) or 
SR141716 (SR1, rimonabant; NIDA Drug Supply Program, SC) $10 \mathrm{mg} / \mathrm{kg}$ intraperitoneally (i.p.), started $1.5 \mathrm{~h}$ before the DOX injection and continued every 24 hours. After 3 (FAAH +/+ and FAAH-/- mice) or 5 (C57BL/6J mice) days animals were subjected either to hemodynamic measurements or sacrificed, hearts were excised and snap frozen in liquid nitrogen for biochemical measurements as previously described [25,28]. For the chronic model (termed cDOX), male 8-12 weeks old FAAH+/+ or FAAH $-/-$ mice were administered with multiple lower doses of DOX (5 mg/kg/dose) i.p. at days 1, 8, 14, and 22 . After 30 days, mice were sacrificed and hearts were excised and snap frozen in liquid nitrogen for biochemical measurements as described [7].

\section{Haemodynamic measurements in mice}

Left-ventricular performance was analyzed in mice anesthetized with $2 \%$ isoflurane using Millar pressure-volume conductance system (Millar Instruments, TX) as described [28,32].

\section{Myocardial 4-hydroxynonenal protein adduct content}

Lipid peroxides are unstable indicators of oxidative stress in cells that decompose to form more complex and reactive compounds such as 4-hydroxynonenal (HNE), which has been shown to be capable of binding to proteins and forming stable adducts. There is also emerging recent evidence implicating HNE in various key signaling processes [33-35]. HNE in the myocardial tissues was determined using a kit (Cell Biolabs, CA). In brief, BSA

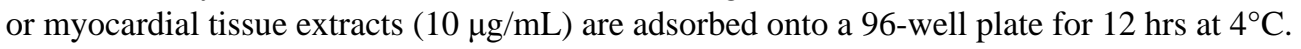
HNE adducts present in the sample or standard are probed with anti-HNE antibody, followed by an HRP conjugated secondary antibody. The HNE-protein adducts content in an unknown sample is determined by comparing with a standard curve and expressed as relative fold change to vehicle.

\section{Myocardial carbonyl content}

Protein oxidation is the covalent modification of a protein induced either directly by reactive oxygen and nitrogen species or indirectly by their reaction with secondary by-products. The most common products of protein oxidation in biological samples are the protein carbonyl derivatives of proline, arginine, lysine, and threonine. These derivatives are chemically stable, have been shown to increase in a variety of diseases and pathological processes, and serve as markers of oxidative stress [36]. Carbonyl content in myocardial tissues was determined by OxiSelect Protein Carbonyl ELISA Kit (Cell Biolabs, CA). In brief, BSA standards or protein samples $(10 \mu \mathrm{g} / \mathrm{mL})$ are adsorbed onto a 96-well plate for $2 \mathrm{hrs}$ at $37^{\circ} \mathrm{C}$. The protein carbonyls present in the sample or standard are derivatized to DNP hydrazone and probed with an anti-DNP antibody, followed by an HRP conjugated secondary antibody. The protein carbonyl content in unknown sample is determined by comparing with a standard curve that is prepared from predetermined reduced and oxidized BSA standards and expressed as relative fold change to vehicle.

\section{Myocardial nitrotyrosine (NT) determination}

Nitrotyrosine formation was initially considered as a specific marker of in vivo peroxynitrite generation, but now it is rather used as a collective index of protein nitration, because other pathways have also been proposed to be involved in its formation (e.g., myeloperoxidase in certain inflammatory conditions [37-40]). Myocardial nitrotyrosine content was determined by nitrotyrosine ELISA according to the protocol supplied with the kit (Hycult Biotechnology, Cell Sciences, Canton, MA) as described [25]. 


\section{Immunoprecipitation for nitrotyrosine detection}

Equal amounts of $200 \mu \mathrm{g}$ tissue homogenate from each sample were incubated with $20 \mu \mathrm{g}$ of NT affinity sorbent (NT antibody cross-linked to a protein A-agarose matrix; Cayman Chemicals, MI) overnight at $4^{\circ} \mathrm{C}$ in a rotating wheel. The NT affinity sorbent is designed for immune-precipitation of nitrated proteins from biological samples. Immuno-precipitates were washed 3 times with PBS containing $0.1 \%$ Triton X-100. Pellets were suspended in $1 \mathrm{x}$ Laemmli buffer with DTT. SDS-PAGE analysis were performed as described earlier followed by silver staining of protein gels [25].

\section{Western blot analysis}

Protein was extracted from myocardial tissue homogenates using tissue protein extraction reagent (TPER), containing protease inhibitor cocktail set III and phosphatase inhibitor cocktail set I (Calbiochem, EMD Biosciences, CA). Protein content was determined using BioRad DC protein assay kit. $50 \mu \mathrm{g}$ of protein was resolved on 4-12\% gradient Bis-Tris Criterion gels (BioRad) and were transferred onto nitrocellulose membrane (GEBiosciences, NY). After blocking, the blots were probed with the primary antibodies (1:1000) $4^{\circ} \mathrm{C}$ overnight. After washing, the blots were incubated with HRP conjugated secondary antibody for $1 \mathrm{hr}$ at room temperature. After final washing, blots were incubated with Super-Signal West Pico chemiluminescense substrate reagent (Pierce Biotechnology, Inc. Rockford, IL) and developed using Kodak Biomax film (PerkinElmer, Wellesley, MA). To verify equal loading the blots were stripped and probed with $\beta$-actin antibody. Developed blots were scanned and the band intensities were determined using Quantity One image analysis program (BioRad, $\mathrm{CA}$ ), normalized to $\beta$-actin and expressed as relative fold change compared to the vehicle or control.

Antibodies were purchased as follows: Cytochrome C(Cyto-C), COX-IV (Cell Signalling Technologies, MA) and $\beta$-actin (Chemicon, CA).

\section{Determination of myocardial glutathione (GSH) content}

Myocardial GSH content was determined using kits from Trevigen (Gaithersburg, MD) according to manufacturer's protocols, as previously reported [25].

\section{Determination of myocardial Caspase 3/7 and poly(ADP-ribose) polymerase (PARP) activities}

Caspase 3/7 activity in the heart homogenates was determined using the fluorimetric based Apo-ONE homogenous assay kit (Promega, Madison, WI) as described [25]. Myocardial PARP activity was assayed using a colorimetric kit according to manufacturer's protocol (Trevigen, Gaithersburg, MD) as described [25].

\section{Myocardial TUNEL Immuno-histochemistry}

Paraffin sections were dewaxed and in situ detection of apoptosis in the myocardial tissues was performed by terminal deoxynucleotodyltransferase mediated nick-end labeling (TUNEL) assay as per the instruction provided with the kit (Roche Diagnostics, Indianapolis). Nucleus was labeled with Hoechst 33242 and the TUNEL positive cells were observed using IX81 Fluorescence microscope (Olympus; using 40X objective).

\section{Myocardial Quantitative TUNEL assay}

Quantitative TUNEL assay was determined using DELFIA DNA fragmentation assay kit [Perkin Elmer Life Sciences, Boston, MA] and was performed in 96 well microplate [Pall Life Sciences, Ann Arbor, MI, USA] as described previously [28]. In brief, equal amount of myocardial total lysates was adsorbed on to the plates, following fixation, then $50 \mu \mathrm{L}$ of 
reaction solution [0.01\% CHAPS buffer, 5.5 units TdT enzyme, $15 \mu \mathrm{M}$ dTTP, $5 \mu \mathrm{M}$ BiodUTP and TdT buffer] and incubated at $37^{\circ} \mathrm{C}$ for $30 \mathrm{~min}$. Then wells were washed with DELFIA plate wash solution. Then Europium labeled streptavidin was diluted in DELFIA assay buffer and incubated for $1 \mathrm{hr}$ at room temperature, after washing, $200 \mu \mathrm{L} /$ well enhancement solution was added and the fluorescence was measured in VICTOR plate reader (Perkin Elmer Life Sciences, Boston, MA).

\section{Myocardial DNA fragmentation ELISA}

The quantitative determinations of cytoplasmic histone-associated-DNA-fragmentation (mono and oligonucleosomes) due to in vivo cell death were measured using ELISA kit (Roche Diagnostics GmbH, Indianapolis)

\section{Measurement of myeloperoxidase activity}

Activity of myeloperoxidase (a marker of neutrophil infiltration) was measured using homogenous fluorometric detection kit (Assay Designs, Plymouth Meeting, PA) in myocardial tissue extracts according to manufacturer's protocol.

\section{Determination of myocardial ROS by electron paramagnetic resonance spectrometer (EPR)}

Myocardial ROS levels were determined by EPR using the spin probe 1-hydroxy-3methoxycarbonyl-2,2,5,5-tetramethylpyrrolidine $(\mathrm{CMH})$ obtained from Enzo Life Sciences (Plymouth Meeting, PA, USA) as described earlier [41,42]. The measurements were performed using Varian X- band EPR system (Walnut Creek, CA, USA) with the following settings: center field $3364 \mathrm{G}$; field sweep $80 \mathrm{G}$; microwave power $20 \mathrm{~mW}$; modulation amplitude $2 \mathrm{G}$; field modulation frequency $100 \mathrm{kHz}$; microwave frequency $9.358 \mathrm{GHz}$ and time constant $64 \mathrm{~ms}$. In brief, 10-15 mg of myocardial tissue from each sample was rinsed thoroughly in $20 \mathrm{mM}$ KHB buffer containing iron chelator $5 \mu \mathrm{M}$ DETC, to remove the contamination and to reduce the artifact. Then the samples were minced with fine scissors and incubated in $\mathrm{KHB}$ buffer containing the spin probe $\mathrm{CMH}(200 \mu \mathrm{M})$ at $37^{\circ} \mathrm{C}$ for $30 \mathrm{~min}$, and then the reaction was arrested by placing the samples in ice. Subsequently an aliquot $(150 \mu \mathrm{L})$ from the samples were loaded on to capillary tubes and ROS levels were determined using EPR system as described above. As CMH can react with superoxide, hydroxyl radical and other reactive oxygen species and used as universal ROS detection trap. In a subset of experiments tissue samples were pre-incubated with superoxide dismutase (Sigma Chemicals, St. Louis, Missouri) at concentration of 400U/tube before $\mathrm{CMH}$ addition to dissect the contribution of superoxide.

\section{Primary cell culture and flow cytometric cell death assay}

Primary human cardiomyocytes were purchased from ScienCell Research Laboratories (Carlsbad, CA) were grown according to manufacturer's recommended media and growth supplements. Cell death were measured using Sytox Green (FL1) and Anenxin V-APC (FL4) in FACScalibur flow cytometer (BD Bioscience, Franklin Lakes, NJ) as described previously $[7,32]$.

\section{Flow cytometric determination of respiratory burst}

For detection of superoxide production we used Dihydrorhodamine 123 (DHR, Invitrogen, Carlsbad, CA) $30 \mathrm{mM}$ stock in DMSO (Sigma Chemicals, St Louis, MO) at a final concentration of $100 \mu \mathrm{M}$ with a modified method of Rothe et al. [43]. Briefly, FAAH+/+ and FAAH $-/-$ mice were deeply anesthetized with isoflurane, and blood was collected after decapitation. We used whole blood for our assay as it has been showed that cell isolation procedures may themselves cause priming and/or activation of neutrophil leukocytes and 
may affect cell function [44]. We diluted the obtained blood 1:1 with Hank's balanced salt solution (HBSS, Mediatech Inc, Herndon, VA) and incubated $5 \mathrm{~min}$ at $37^{\circ} \mathrm{C}$. Then cells were then incubated with DHR and catalase (1000 U/ml, Sigma Chemicals, St Louis, MO) in the dark at $37^{\circ} \mathrm{C}$ for 20 minutes. Thereafter, we placed the samples on ice and lyzed the erythrocytes with ACK lyzing buffer (Quality Biological, Gaithersburg, MD), and the remaining leukocytes were washed 3 times with HBSS. Cells loaded with DHR were treated with anandamide (AEA) and phorbol ester (PMA) as indicated concentration for 30 mins and DHR intensity were measured by flow cytometry (FACS Calibur, BD Bioscience) in FL1 channel [45]. Polymorphonuclear neutrophils were gated on the basis of their forward scatter (FSC) and side scatter (SSC) properties. Kinetics of the same experiments were also carried out in parallel experiment in plate based assay using Fluorescence plate reader (Victor, Perkin Elmer, Boston, MA).

\section{Statistical analysis}

Results are expressed as mean \pm SEM. Statistical significance among groups was determined by one-way ANOVA followed by Newman-Keuls post hoc analysis using GraphPad Prism 5 software (San Diego, CA). Correlation analyses were carried out as pairwise using the same program. Kaplan-Meier survival analysis and curve fitting was also performed using GraphPad Prism 5 software (San Diego, CA). Probability values of $P<0.05$ were considered significant.

\section{Results}

Acute or chronic DOX-treatment is associated with similar changes in body weights in $\mathrm{FAAH}+/+$ or $\mathrm{FAAH}-/-$ mice. There is no difference in the initial body weights of these 7-12 weeks old male mice kept on regular diet

Since increased endocannabinoid levels may promote increased food intake, in some mice body weights were also measured before the DOX administration and at various time points following DOX administration. The body weight of FAAH+/+ and FAAH-/- mice before the acute DOX administration and at a time of the sacrifice 3 days later were $20.7 \pm 0.3$, $19.5 \pm 0.6,17.2 \pm 0.3 ; 16.9 \pm 0.6$ ( $\mathrm{n}=10 /$ group), respectively. The body weight of FAAH+/+ and FAAH-/- mice before the chronic DOX administration and at a time of the sacrifice 30 days later were $23.8 \pm 0.6,23.4 \pm 1.0,21.0 \pm 0.5 ; 21.7 \pm 1.0$ ( $\mathrm{n}=11-12$ /group), respectively.

\section{Cannabinoid $\mathrm{CB}_{1}$ receptor inhibition attenuates acute DOX-induced increased myocardial oxidative/nitrative stress and impaired antioxidant defense}

Administration of a single dose of DOX ( $20 \mathrm{mg} / \mathrm{kg}$ i.p.) was associated with 5.5 -fold increase in marker of oxidative stress HNE (Figure 1A) and 4.9-fold increase in marker of nitrative stress nitrotyrosine (Figure 1B-C), associated with a 44\% percent decrease in total glutathione content (Figure 1D) in the myocardium of mice 5 days following acute DOX administration. These changes were significantly attenuated by treatment of mice with $\mathrm{CB}_{1}$ antagonists AM281 (by 24\%, 30\% and 36\% respectively) and SR141716 (rimonabant, by $33 \%, 50 \%$ and $54 \%$, respectively).

\section{Cannabinoid $\mathrm{CB}_{1}$ receptor inhibition attenuates acute DOX-induced increased myocardial cytochrome $C$ release and cell death}

As shown in Figure 2A and quantified in Figure 2B, representative immunoblots reveal 8.4fold enhanced cytochrome $\mathrm{C}$ release into the cytosol in the myocardial tissues of DOXtreated mice (indicative of the activation of mitochondrial apoptotic cell death pathway) and its attenuation with $\mathrm{CB}_{1}$ receptor antagonists AM281 and SR141716 (55 and $60 \%$ attenuation). The cytosolic Cyto-C is normalized to $\beta$-actin, while mitochondrial to $\mathrm{COX}$ - 
IV. Figure 2 panels $\mathrm{C}$ and D demonstrate a 4-fold increase in myocardial caspase 3/7(marker of apoptotic cell death) and a 5.8-fold increase in poly(ADP-ribose)polymerase (PARP)-dependent cell death (mostly necrotic cell death) after doxorubicin administration, which were attenuated by $\mathrm{CB}_{1}$ antagonists $\mathrm{AM} 281(-38.75 \%$ and $-45 \%)$ and SR141716 $(-50 \%$ and $-43 \%)$.

\section{Genetic deletion of FAAH is associated with enhanced acute DOX-induced myocardial cell death and decreased survival}

As shown in Figure 3A FAAH-/- mice treated with DOX had markedly reduced survival, compared to their wild type $(\mathrm{FAAH}+/+)$ littermates. Due to significantly reduced survival rate in DOX-treated FAAH-/- mice at 5 days (Figure 3A) experiments shown in Figures 311 were carried out 3 days following the DOX treatment (at this time point the survival rate in FAAH+/+ mice treated with DOX was $100 \%$ and only less than $20 \%$ of the FAAH-/mice treated with the drug were lost). Figure 3B-E shows markedly increased myocardial cell death (both apoptotic and PARP-dependent) in FAAH-/- mice treated with DOX compared to their wild type (FAAH+/+) littermates.

\section{Genetic deletion of FAAH is associated with enhanced time-dependent acute DOX-induced myocardial oxidative and nitrative stress}

As shown in Figure 4A-D FAAH-/- mice treated with DOX had markedly increased oxidative (HNE, carbonyl) and nitrative (nitrotyrosine) stress in the myocardium compared to their wild type $(\mathrm{FAAH}+/+)$ littermates and attenuated antioxidant defense (decreased total glutathione content). To better understand the mechanisms of doxorubicin-induced cardiomyopathy in FAAH+/+ and FAAH-/- mice we further analyzed the time-dependence of the above mentioned markers of oxidative and nitrative stress and cell death 2, 6, 12, 24, 24, 48, and 72 hours following the DOX administration (Figure 5). We found significant increases in markers of cell death from 12 or 24 hours following the DOX administration in FAAH $-/-$ and FAAH+/+ mice, which were markedly enhanced in knockouts (Figure 5AB). Similar time-dependent increases (larger in FAAH-/- mice) were seen with HNE (Figure 5C; marker of oxidative stress) from 6 hours following the DOX administration, and with nitrotyrosine (Figure 5D, marker of peroxynitrite generation and nitrative stress) from 12 and 48 hours following DOX administration in FAAH $-/-$ and FAAH $+/+$ mice, respectively. The increase in myocardial oxidative and nitrative stress paralleled with decreased myocardial reduced and total glutathione content (Figure 5E-F). Interestingly, there was only a modest increase $(\sim 30 \%)$ in the myocardial myeloperoxidase (MPO) activity (indicator of neutrophil infiltration) at 72 hours following DOX administration in FAAH+/+ mice, while significant increases could be detected in the myocardium of FAAH-/- mice from 6 hours following DOX exposure, reaching 167\% increase at 72 hours compared to FAAH+/+ mice. Collectively, these results suggest that the DOX-induced oxidative stress precedes the nitrative stress and cell death and leads to the depletion of the cellular reduced glutathione content. Furthermore, the increased neutrophil infiltration in myocardial tissues of FAAH -/- mice treated with DOX compared to their FAAH+/+ littermates may explain, at least in part, the increased oxidative and nitrative stress coupled with greater impairment of the antioxidant defense and increased cell death in knockouts.

\section{The markers of acute DOX-induced myocardial oxidative and nitrative stress correlate with cell death and decrease of reduced glutathione content}

To further explore the mechanism of the DOX-induced myocardial cell death in FAAH+/+ and FAAH $-/-$ mice we correlated changes in myocardial cell death and oxidative stress markers on a per animal basis in both strains, and studied the differences between different genotypes. As shown in Figure 6A-D, we observed a positive correlation between oxidative and nitrative stress markers (HNE and nitrotyrosine) and the apoptotic cell death marker 
caspase 3-7 activity, and a negative correlation of HNE and nitrotyrosine with reduced glutathione content. These correlations were stronger in FAAH-/- mice.

The enhanced acute DOX-induced myocardial ROS generation in FAAH-/- mice is attenuated by $\mathrm{CB}_{1}$ antagonists

As shown in Figures 7 and 8A-D, the markedly increased DOX-induced myocardial ROS/ RNS generation in FAAH-/- mice, was attenuated by $\sim 40-50 \%$ with $\mathrm{CB}_{1}$ antagonists SR141716 and AM281. The EPR probe CMH directly reacts with superoxide, hydrogen peroxide, and hydroxyl radical $(\bullet \mathrm{OH})$ or hydroxyl radical derived secondary radicals, forming the nitroxide radical, which is detectable by EPR. Therefore the representative EPR traces shown on the figure 7 only depict general ROS in the myocardium. Though one molecule of superoxide oxidizes one molecule of $\mathrm{CMH}$ to corresponding nitroxide radical form, this is redox cycle reaction and bio-reduction by reducing agents and reductases existing in the system to the hydroxylamine form is not negligible, therefore this EPR experiment provides only semi-quantitative aspect of ROS production in the system. Also, we couldn't distinguish if the origin of ROS is mitochondria in this experimental design. Addition of SOD to the samples in this experimental design resulted in $\sim 40-50 \%$ reduction in ROS production in all experimental groups (data not shown), indicating that superoxide is most likely one of the form of the ROS formed in the myocardium of DOX treated mice. Upper panel in figure 7 shows representative EPR traces and the quantification is shown below.

The enhanced acute DOX-induced myocardial cell death in FAAH-/- mice is attenuated by $\mathrm{CB}_{1}$ antagonists

As shown in Figures 9A-D and 10A-B, the markedly increased DOX-induced myocardial cell death (both apoptotic and necrotic) in FAAH-/- mice, was attenuated by $\mathrm{CB}_{1}$ antagonists SR141716 and AM281. In Figure 10A the upper row of images (green) shows representative TUNEL staining, the middle row (dark blue) is the nuclear staining, while the bottom one is the colocalization of both (light blue/white nuclei represents TUNEL positive cells).

\section{FAAH-/- mice develop more severe acute DOX-induced cardiac dysfunction}

Markers of left ventricular contractile function (maximum first derivative of ventricular pressure with respect to time (+dP/dt), maximal left ventricular pressure (LVP), ejection fraction, stroke work and cardiac output) were decreased 3 days following DOX exposure in FAAH+/+ and FAAH-/- mice. The DOX-induced myocardial dysfunction was significantly more pronounced in FAAH-/- mice compared to their wild type littermates (Figure 11A-B) and was improved by CB1 antagonists SR141716 or AM281 treatment (Figure 11A-B).

\section{Genetic deletion of FAAH is associated with enhanced chronic DOX-induced myocardial oxidative-nitrative stress and cell death}

We also wanted to confirm our findings in a chronic model of DOX-induced cardiomyopathy described previously [7]. In this chronic model all mice survived in the wild-type group, while the survival rate was 92 percent in the FAAH-/- group at 30 days following 4 multiple doses $(5 \mathrm{mg} / \mathrm{kg}$ each) of DOX as described in the methods. We found a $\sim 3$-4 fold increases in cell death and oxidative-nitrative stress markers after 30 days of DOX treatment, which was further enhanced by $\sim 50-70 \%$ in FAAH $-/-$ mice, thus validating our findings in the acute model (Figure 12). 
Myocardial oxidative and nitrative stress markers show direct positive correlation with cell death markers and negative correlation with reduced glutathione content after chronic administration of a sublethal dose doxorubicin

The oxidative-nitrative stress markers showed similar correlation in the chronic treatment group to what we observed after the acute doxorubicin treatment (Figure 13A-F). We observed positive correlation between oxidative (HNE) and nitrative (nitrotyrosine) stress markers and the apoptotic cell death markers (caspase 3-7 activity and DNA fragmentation), and a negative correlation with reduced glutathione content (Figure 13A-F), and these correlation were stronger in FAAH-/- mice (Figure 13A-F).

\section{Anandamide causes enhanced cell death in cardiomyocytes and increased ROS production in neutrophils, which are enhanced by FAAH inhibition or genetic deletion}

To explain our in vivo findings we carried out in vitro experiments. The endocannabinoid anandamide (AEA) caused concentration-dependent cell death in human primary cardiomyocytes, which was further enhanced in the presence of FAAH inhibitor URB527 (Figure 14A).

There was no significant difference in the baseline ROS levels in neutrophils of FAAH+/+ and FAAH $-/-$ mice. However, AEA triggered concentration-dependent respiratory burst (ROS generation) in neutrophil granulocytes isolated from FAAH+/+ mice (comparable to the positive control phorbol ester (PMA)); the sensitivity to AEA was enhanced in FAAH-I - mice (Figure 14B). However, the response to PMA on neutrophil oxidative burst was not different in FAAH+/+ and FAAH-/- mice indicating that the maximal inducible ROS generation is similar in both strains (only the sensitivity to AEA-induced ROS generation was different). Taken together, the above mentioned results suggest that the increase in AEA level in neutrophils associated with genetic deletion of FAAH-I- is not sufficient to activate the increased ROS generation in these cells by itself (probably in these cells alternative metabolic pathways keep AEA levels below the threshold sufficient for the activation). However, the higher level of AEA required to cross the threshold of triggering ROS generation in neutrophils, may be achieved in pathological situations in which the endocannabinoid synthetic pathways are activated concurrently with inhibition of metabolic degradation by excessive oxidative/nitrative stress and/or inflammation, or alternatively when large amount of AEA is released from damaged or dying cells (the latter is also a quite likely possibility in light of the previously reported postmortem generation of anandamide and other long-chain $\mathrm{N}$-acylethanolamines in mammalian brain). Furthermore, in injured tissues where cells are already damaged/stressed by inflammatory stimuli or reactive oxygen/nitrogen species, lower levels of AEA may be required to trigger or amplify the pathological process of ROS generation.

\section{Discussion}

In this study, we have investigated the role of the key endocannabinoid metabolizing enzyme FAAH and the endocannabinoid signaling mediated through cannabinoid $1\left(\mathrm{CB}_{1}\right)$ receptors, in the development of acute myocardial injury induced by a very important chemotherapeutic agent doxorubicin (DOX), known for its cardiotoxicity mediated by increased reactive and nitrogen species generation [22-25,29,30], utilizing well-established acute and chronic cardiomyopathy models in mice $[7,24-28]$, in which increased myocardial endocannabinoid levels and $\mathrm{CB}_{1}$ receptors were implicated in the development of cardiac dysfunction [28] and cell death [7]. We have also explored the interplay of oxidative/ nitrative stress and cell death pathways with $\mathrm{CB}_{1}$ receptors in the acute model of cardiomyopathy by using pharmacological antagonists of the cannabinoid $\mathrm{CB}_{1}$ receptor (SR141716 (rimonabant) and AM281). 
First we show that pharmacological inhibition of $\mathrm{CB}_{1}$ receptors with AM281 or SR141716 attenuates DOX-induced increased oxidative/nitrative stress and interrelated cell death. These findings, coupled with recent studies in $\mathrm{CB}_{1}$ knockout mice [7] suggest that $\mathrm{CB}_{1}$ cannabinoid receptor activation by endocannabinoids may promote DOX induced myocardial injury by amplifying cell death pathways and the associated oxidative/nitrative stress. Consistently, $\mathrm{CB}_{1}$ activation also promotes oxidative/nitrative stress in an experimental model of nephropathy induced by another important chemotherapeutic drug cisplatin [46].

FAAH is a key controller of tissue anandamide levels, because of the very rapid metabolism, which is also reflected by the fact that high doses of endocannabinoids exert only very brief hemodynamic effects (for a couple of minutes) in normal mice [47], but these are considerably more prolonged in FAAH knockouts [31]. Despite approximately 2.5 fold increase in the myocardial anandamide levels FAAH knockout mice have normal hemodynamic profile [31], consistent with the limited physiological role of the endocannabinoid system in normal cardiovascular regulation [2]. However, under various pathological conditions, as already mentioned in the introduction section, this system through the activation of $\mathrm{CB}_{1}$ receptors by the endocannabinoid anandamide promotes cardiovascular or other types of tissue injury and may also contributes to the development of increased cardiovascular risk factors in humans [3]. In fact, FAAH appears to be a key determinant of anandamide-induced cell death and ROS generation in hepatocytes, and FAAH knockout mice following bile duct ligation exhibit markedly increased hepatocellular injury [21].

Our results also demonstrate markedly increased DOX-induced myocardial oxidativenitrative stress and tissue injury in FAAH-/- mice compared to their wild type littermates, which coupled with the decreased survival as a consequence of the DOX-induced acute cardiac dysfunction/failure, strongly suggests that in pathological conditions associated with acute oxidative/nitrative stress FAAH plays a key role in controlling the anandamideinduced myocardial cell death/injury, which is, at least in part, mediated by the activation of $\mathrm{CB}_{1}$ receptors by endocannabinoids, since these effects could be attenuated by selective $\mathrm{CB}_{1}$ antagonists. Therefore, $\mathrm{CB}_{1}$ inhibition may exert beneficial effects in cardiovascular (and most likely other) diseases associated with oxidative/nitrative stress and cell death.

Recent studies indeed have suggested that $\mathrm{CB}_{1}$ receptor antagonists may exert protective effects in multiple preclinical disease models ranging from hepatic steatosis [48], ischemicreperfusion injury [49], endotoxin shock [50,51], to atherosclerosis $[9,10,16]$ and cardiomyopathy [7]. Chronic rimonabant treatment decreases the elevated serum/plasma levels of TNF- $\alpha$, RANTES (Regulated on Activation, Normal T cell Expressed, and Secreted) and MCP-1, restored plasma levels of the anti-inflammatory hormone adiponectin, in obese Zucker fa/fa rats [52], and decreased NF-kappaB activation and consequent iNOS expression in mitogen-stimulated human peripheral blood mononuclear cells [53]. In clinical trials rimonabant (SR141716) also attenuated multiple inflammatory markers (e.g. TNF $\alpha, \mathrm{C}-$ reactive protein, etc), plasma leptin and insulin levels, and increased plasma adiponectin in obese patients with metabolic syndrome and/or type 2 diabetes $[3,16]$.

In the context of DOX-induced cardiomyopathy, the above mentioned effect of rimonabant on NF-kappaB activation, and expression of iNOS may be particularly relevant, since oxidative/nitrative stress is crucial mediator in the pathogenesis of doxorubicin-induced myocardial injury. It is possible that some of the beneficial effects of $\mathrm{CB}_{1}$ antagonists observed in our model, for example decreased nitrotyrosine generation, could be at least in part mediated by inhibition of NF-kappaB-iNOS pathway. Indeed, DOX-induced oxidative and nitrative stress [24,25,27,54-57], and the associated activation of various cell death 
pathways (e.g. p38, JNK MAPKs, PARP; [26,58]) play an important role in the pathogenesis of cardiac dysfunction [59]. Interestingly, increased tissue and/or serum endocannabinoid levels during reperfusion injury positively correlate with tissue damage and cell death in experimental models of hepatic ischemic-reperfusion $[13,49,60]$ and stroke [61]. There is rising acknowledgment that in various pathological conditions $\mathrm{CB}_{1}$ receptor activation by endocannabinoids may promote activation of stress signaling pathways (e.g. p38 and JNK MAPKs) facilitating cell demise [6,7,46,62]. Furthermore, oxidative/nitrative stress may also increase tissue endocannabinoid levels $[13,49]$, presumably by inactivation of the metabolizing enzyme(s) [7] and/or by increasing the activity of the synthetic pathways.

In agreement with earlier reports we found that DOX in both acute and chronic murine models of cardiomyopathies markedly increased myocardial oxidative (increased HNE and carbonyl protein adducts) and nitrative stress (increased myocardial nitrotyrosine generation) [22,24,25,27,29,30], accompanied by decreased antioxidant defense (reduced glutathione levels) and activation of downstream effector cell death pathways (e.g. PARP) crucially involved in the development of doxorubicin-induced cell demise of cardiomyocytes and/or endotheial cells, and subsequent cardiomyopathy [24-27]. While nitrotyrosine has been considered a marker of peroxynitrite formation previously, there is growing evidence that heme-protein peroxidase activity, in particular neutrophil-derived myeloperoxidase (MPO), significantly contributes to nitrotyrosine formation in vivo via the oxidation of nitrite to nitrogen dioxide [37-39]. However, in the acute and chronic models of DOX-induced cardiomyopathies the myocardial inflammatory component is only minimal [7,24-26] and the DOX-induced increased nitrotyrosine staining is localized in cardiomyocytes and endothelial cells [24,25,63]. Furthermore, DOX also increases nitrotyrosine generation in cardiomyocytes in vitro and peroxynitrite decomposition catalysts are effective in attenuating DOX-induced cardiac dysfunction and cell death both in animal models of cardiomyopathy, as well as in vitro in cardiomyocytes $[25,27]$. The absence of the significant inflammatory component in this cardiomyopathy model is also supported by only minimal increase of MPO activity in hearts of DOX exposed FAAH+/+ mice at 3 days, at a time when cardiac dysfunction develops. Therefore, the increased myocardial nitrotyrosine generation in FAAH $+/+$ mice in the acute model of DOX-induced cardiomyopathy most likely originates from increased endogenous peroxynitrite generation in cardiomyocytes and endothelial cells. Interestingly, while there was only a modest increase $(-30 \%)$ in the myocardial MPO activity at 72 hours following DOX administration in FAAH+/+ mice, significant increases could be detected in the myocardium of FAAH-/mice relatively early (from 6 hours following DOX exposure), reaching peak $\sim 167 \%$ increase at 72 hours compared to FAAH+/+ mice. Therefore, in FAAH-/- mice a minor contribution of inflammatory cells' derived MPO to NT generation cannot be excluded, and these inflammatory cells can also contribute to the increased ROS and RNS generation observed in these animals compared to their wide type littermates, in addition to endothelial cells and cardiomyocytes. Similar results were also seen in the chronic model of DOXinduced cardiomyopathy, where even in FAAH+/+ mice a small inflammatory component appeared to be present.

We observed a time-dependent increase in myocardial nitrotyrosine formation following acute DOX exposure of mice peaking at days 3-5 [25] coinciding with the fully developed myocardial dysfunction in this model. We also found that the myocardial nitrotyrosine levels positively correlated with markers of cell death both in acute and chronic DOX-induced cardiomyopathy models and negatively with tissue reduced glutathione levels in FAAH+/+ mice. These correlations were similar, but stronger in FAAH-/- mice. There is also a highly significant inverse relationship between DOX-induced left ventricular fractional shortening and cardiac nitrotyrosine immunoprevalence [24], and the development of DOX-induced left 
ventricular dysfunction parallels with the increases of the myocardial nitrotyrosine levels [25], supporting a key role of the endogenous peroxynitrite generation in mediationg DOXinduced cardiotoxicity.

Similar to the above described for NT (larger in FAAH-/- mice) time-dependent changes in myocardial HNE protein adducts (marker of lipid peroxidation and oxidative stress) were seen in acute DOX exposed mice (slightly preceding the nitrative stress), which also paralleled with increased cell death and decreased myocardial reduced and total glutathione content; the latter also suggests that the DOX-induced secondary ROS/RNS generation was most likely responsible for the depletion of myocardial glutathione rather than a direct effect of DOX itself. On the basis of our markers of ROS we cannot precisely predict the types of ROS involved in the observed effects, however the findings that preincubation of hearts from DOX-treated mice with SOD in EPR experiments resulted in 40-50\% reduction of the overall signal (data not shown) indicate that superoxide was involved.

While the most likely source of increased myocardial reactive oxygen species generation by DOX in the acute cardiomyopathy model is the mitochondrion $[25,29,64]$, additional contribution from the increased activity of the NADPH oxidases (without increased mRNA expression) cannot be excluded in vivo [25,27]. Indeed, in the chronic DOX-induced cardiomyopathy model the expression of several isoformes of NADPH oxidases are secondarily increased, which are most likely contributing to the DOX-induced increased ROS generation [7]. Inducible nitric oxide synthase appears to be involved in DOX-induced increased nitrative stress $[24,25,27]$. The increased DOX-induced superoxide and nitric oxide generation facilitates the formation of reactive oxidant peroxynitrite [40], which may impair cardiac function via multiple interrelated mechanisms, including but not limited to promoting apoptotic and PARP-dependent cell death [65,66]. Indeed, peroxynitrite is a key trigger of cell death in cardiomyocytes and endothelial cells during ischemic-reperfusion injury $[67,68]$, as well as in both in vivo and in vitro models of DOX-induced cardiomyopathy $[25,69]$. Consistent with the DOX-induced mitochondrial dysfunction and activation of mitochondrial cell death pathways, we found increased cyto-C release from the mitochondria to cytosol, and activation of caspase 3/7 in myocardium of DOX-treated mice. Most likely DOX initially increases mitochondrial superoxide and, consequently, the generation of other ROS (e.g., $\mathrm{H}_{2} \mathrm{O}_{2}$ ) in cardiomyocytes and/or endothelial cells by redox cycling $[25,30]$. Increased DOX-induced ROS generation in cardiomyocytes and endothelial cells triggers the activation of the transcription factor NF-kappaB [70], leading to enhanced iNOS expression and NO generation [24,25]. NO, irrespective of its source (other sources such as eNOS may also contribute to NO generation), diffuses freely and reacts with superoxide to form peroxynitrite both in the cytosol and mitochondria, which, in turn, induces cell damage via lipid peroxidation, inactivation of enzymes and other proteins by oxidation and nitration, and activation of stress signaling pathways (e.g., MAPK), MMPs, and PARP-1, among others [65]. In the mitochondria, peroxynitrite, in concert with other ROS/reactive nitrogen species, impairs various key mitochondrial enzymes, leading to more sustained intracellular ROS generation (persistent even after DOX already metabolized), triggering further activation of transcription factor(s) and iNOS expression, resulting in the amplification of oxidative/nitrative stress $[40,65,66]$. In the mitochondria, peroxynitrite also triggers the release of proapoptotic factors (e.g., Cyt-C and apoptosis-inducing factor) mediating caspase-dependent and -independent cell death pathways, which are also pivotal in DOX-induced cardiotoxicity [25]. Peroxynitrite, together with other oxidants, also causes strand breaks in DNA, activating the nuclear enzyme PARP-1 dependent cell death pathways (mostly necrotic) [26]. Overactivated PARP may also facilitate the expression of a variety of inflammatory genes leading to increased inflammation (PARP-1 is a known coactivator of NF-kappaB) and associated oxidative stress, thus facilitating the progression of cardiovascular dysfunction and heart failure [71]. 
Collectively, the DOX-induced above mentioned pathological alterations were markedly enhanced in FAAH-/- mice compared to their wild type FAAH+/+ littermates. The DOXinduced oxidative and nitrative stress strongly correlated with myocardial cell death and dysfunction. Oxidative/nitrative stress and inflammation increases endocannabinoid levels in inflammatory as well as parenchyma cells by either enhancement of the biosynthetic pathways or by inactivation of the endocannabinoid metabolizing enzymes such as FAAH (a key regulator of the tissue AEA levels because of the rapid metabolism) [13,49]. Various oxidants (e.g. peroxynitrite, $\mathrm{H}_{2} \mathrm{O}_{2}$ ) and inflammatory stimuli (endotoxin, TNF-alpha) increase endocannabinoid levels in parenchyma and or inflammatory cells [49,61]. Similarly, DOX in cardiomyocytes in vitro and in mouse hearts increases AEA levels [28], most likely as a secondary consequence of ROS/RNS generation, which can lead to inactivation of metabolic enzyme(s) or enhanced endocannabinoid synthesis. Indeed, decreased activity of FAAH has recently been reported in a rodent model of DOX-induced cardiomyopathy [7], which may be responsible for the increased AEA levels in vivo [28]. Consequently, AEA (or perhaps other fatty acid amides) by activating $\mathrm{CB}_{1}$ receptors in plasma membranes of cardiomyocytes [7], endothelial [6,72] and inflammatory cells [8] or $\mathrm{CB}_{1}$ receptor-independent pathways can trigger increased reactive oxygen species production, MAPK activation, and cell death. Fatty acid amides such as AEA most likely may primarily influence ROS generation and the increase in nitrative stress is only the secondary consequence of increased ROS generation. In addition, the increased neutrophil infiltration in myocardial tissues of FAAH-/- mice treated with DOX compared to their FAAH+/+ littermates may explain, at least in part, the increased oxidative and nitrative stress coupled with greater impairment of the antioxidant defense and increased cell death in knockouts. Isolated inflammatory cells from FAAH-/- mice exhibited higher sensitivity to AEA-induced ROS generation compared to cells of FAAH+/+ mice without difference in the maximal ROS production induced by PMA. The enhanced inflammatory cell infiltration in myocardium of DOX treated FAAH-/- mice is consistent with the recently found unexpected role of $\mathrm{CB}_{1}$ receptors in inflammatory cell migration associated with atherosclerosis $[9,10]$, demonstrating that endocannabinoids and $\mathrm{CB}_{1}$ receptors on immune cells are involved in promoting vascular inflammatory response.

The beneficial effects of $\mathrm{CB}_{1}$ blockade in DOX induced cardiomyopathy models may comprise of: a) attenuation of the $\mathrm{CB}_{1}$ receptor-dependent cardiodepressive effects of AEA, b) decrease of the AEA-induced ROS generation, MAPK activation and cell death in endothelial cells, cardiomyocytes and inflammatory cells, c) decrease in inflammatory cell infiltration and secretion of pro-inflammatory mediators (e.g. TNF-alpha) by these cells, and d) attenuation of the NFkappaB-iNOS pathway resulting in decreased NO generation and consequent peroxynitrite formation through the diffusion limited reaction of superoxide with NO.

Thus, in pathological conditions associated with marked oxidative/nitrative stress without major inflammatory cell component (like in our DOX-induced cardiomyopathy models), FAAH plays a key role in controlling the endocannabinoid anandamide-induced myocardial cell death/tissue injury, which is, at least in part, mediated by the activation of cardiovascular $\mathrm{CB}_{1}$ receptors. Conversely, pharmacological inhibition of $\mathrm{CB}_{1}$ exerts beneficial effects against DOX-induced cardiotoxicity by attenuating the vicious circle of the above mentioned overactivated pathological pathways, which coupled with a recent study demonstrating that it also inhibits human colon cancer cell growth and reduces the formation of precancerous lesions in the mouse colon [73], and emerging development of peripherally restricted novel $\mathrm{CB}_{1}$ antagonists [74,75], are very exciting. 


\section{Acknowledgments}

This study was supported by the Intramural research program of the National Institutes of Health/NIAAA (to P.P.). Dr. Horváth was supported by an NKTH-OTKA-EU 7FW Fellowship (MB08-A 80238). Authors are indebted to Dr. Murali C. Krishna for generously providing his resources and expertise with EPR measurements and Dr. George Kunos for providing support and resources for the completion of this study.

\section{References}

1. Howlett AC, Barth F, Bonner TI, Cabral G, Casellas P, Devane WA, Felder CC, Herkenham M, Mackie K, Martin BR, Mechoulam R, Pertwee RG. International Union of Pharmacology. XXVII. Classification of cannabinoid receptors. Pharmacol Rev 2002;54:161-202. [PubMed: 12037135]

2. Pacher P, Batkai S, Kunos G. The endocannabinoid system as an emerging target of pharmacotherapy. Pharmacol Rev 2006;58:389-462. [PubMed: 16968947]

3. Pacher P, Steffens S. The emerging role of the endocannabinoid system in cardiovascular disease. Semin Immunopathol 2009;31:63-77. [PubMed: 19357846]

4. Pacher P, Mukhopadhyay P, Mohanraj R, Godlewski G, Batkai S, Kunos G. Modulation of the endocannabinoid system in cardiovascular disease: therapeutic potential and limitations. Hypertension 2008;52:601-607. [PubMed: 18779440]

5. Batkai S, Pacher P. Endocannabinoids and cardiac contractile function: pathophysiological implications. Pharmacol Res 2009;60:99-106. [PubMed: 19569260]

6. Rajesh M, Mukhopadhyay B, Hasko G, Liaudet L, Mackie K, Pacher M. Cannabinoid-1 receptor activation induces reactive oxygen species-dependent and -independent mitogen-activated protein kinase activation and cell death in human coronary artery endothelial cells. Br J Pharmacol 2010;160:688-700. [PubMed: 20590572]

7. Mukhopadhyay P, Rajesh M, Batkai S, Patel V, Kashiwaya Y, Liaudet L, Evgenov OV, Mackie K, Hasko G, Pacher P. CB1 cannabinoid receptors promote oxidative stress and cell death in murine models of doxorubicin-induced cardiomyopathy and in human cardiomyocytes. Cardiovasc Res 2010;85:773-784. [PubMed: 19942623]

8. Han KH, Lim S, Ryu J, Lee CW, Kim Y, Kang JH, Kang SS, Ahn YK, Park CS, Kim JJ. CB1 and $\mathrm{CB} 2$ cannabinoid receptors differentially regulate the production of reactive oxygen species by macrophages. Cardiovasc Res 2009;84(3):378-386. [PubMed: 19596672]

9. Dol-Gleizes F, Paumelle R, Visentin V, Mares AM, Desitter P, Hennuyer N, Gilde A, Staels B, Schaeffer P, Bono F. Rimonabant, a selective cannabinoid CB1 receptor antagonist, inhibits atherosclerosis in LDL receptor-deficient mice. Arterioscler Thromb Vasc Biol 2009;29:12-18. [PubMed: 18845788]

10. Sugamura K, Sugiyama S, Nozaki T, Matsuzawa Y, Izumiya Y, Miyata K, Nakayama M, Kaikita K, Obata T, Takeya M, Ogawa H. Activated endocannabinoid system in coronary artery disease and antiinflammatory effects of cannabinoid 1 receptor blockade on macrophages. Circulation 2009;119:28-36. [PubMed: 19103987]

11. Rajesh M, Mukhopadhyay P, Hasko G, Pacher P. Cannabinoid CB1 receptor inhibition decreases vascular smooth muscle migration and proliferation. Biochem Biophys Res Commun 2008;377:1248-1252. [PubMed: 18996082]

12. Montecucco F, Lenglet S, Braunersreuther V, Burger F, Pelli G, Bertolotto M, Mach F, Steffens S. $\mathrm{CB}(2)$ cannabinoid receptor activation is cardioprotective in a mouse model of ischemia/ reperfusion. J Mol Cell Cardiol 2009;46:612-620. [PubMed: 19162037]

13. Batkai S, Osei-Hyiaman D, Pan H, El-Assal O, Rajesh M, Mukhopadhyay P, Hong F, HarveyWhite J, Jafri A, Hasko G, Huffman JW, Gao B, Kunos G, Pacher P. Cannabinoid-2 receptor mediates protection against hepatic ischemia/reperfusion injury. FASEB J 2007;21:1788-1800. [PubMed: 17327359]

14. Mukhopadhyay P, Rajesh M, Pan H, Patel V, Mukhopadhyay B, Batkai S, Gao B, Hasko G, Pacher P. Cannabinoid-2 receptor limits inflammation, oxidative/nitrosative stress, and cell death in nephropathy. Free Radic Biol Med 2010;48:457-467. [PubMed: 19969072]

15. Di Marzo V, Cote M, Matias I, Lemieux I, Arsenault BJ, Cartier A, Piscitelli F, Petrosino S, Almeras N, Despres JP. Changes in plasma endocannabinoid levels in viscerally obese men 
following a 1 year lifestyle modification programme and waist circumference reduction: associations with changes in metabolic risk factors. Diabetologia 2009;52:213-217. [PubMed: 18972095]

16. Pacher P. Cannabinoid CB1 receptor antagonists for atherosclerosis and cardiometabolic disorders: new hopes, old concerns? Arterioscler Thromb Vasc Biol 2009;29:7-9. [PubMed: 19092136]

17. Cravatt BF, Giang DK, Mayfield SP, Boger DL, Lerner RA, Gilula NB. Molecular characterization of an enzyme that degrades neuromodulatory fatty-acid amides. Nature 1996;384:83-87. [PubMed: 8900284]

18. Ahn K, McKinney MK, Cravatt BF. Enzymatic pathways that regulate endocannabinoid signaling in the nervous system. Chem Rev 2008;108:1687-1707. [PubMed: 18429637]

19. Cravatt BF, Demarest K, Patricelli MP, Bracey MH, Giang DK, Martin BR, Lichtman AH. Supersensitivity to anandamide and enhanced endogenous cannabinoid signaling in mice lacking fatty acid amide hydrolase. Proceedings of the National Academy of Sciences of the United States of America 2001;98:9371-9376. [PubMed: 11470906]

20. Cravatt BF, Saghatelian A, Hawkins EG, Clement AB, Bracey MH, Lichtman AH. Functional disassociation of the central and peripheral fatty acid amide signaling systems. Proceedings of the National Academy of Sciences of the United States of America 2004;101:10821-10826. [PubMed: 15247426]

21. Siegmund SV, Seki E, Osawa Y, Uchinami H, Cravatt BF, Schwabe RF. Fatty acid amide hydrolase determines anandamide-induced cell death in the liver. J Biol Chem 2006;281:1043110438. [PubMed: 16418162]

22. Kotamraju S, Konorev EA, Joseph J, Kalyanaraman B. Doxorubicin-induced apoptosis in endothelial cells and cardiomyocytes is ameliorated by nitrone spin traps and ebselen. Role of reactive oxygen and nitrogen species. J Biol Chem 2000;275:33585-33592. [PubMed: 10899161]

23. Wang S, Konorev EA, Kotamraju S, Joseph J, Kalivendi S, Kalyanaraman B. Doxorubicin induces apoptosis in normal and tumor cells via distinctly different mechanisms. intermediacy of $\mathrm{H}(2) \mathrm{O}(2)-$ and p53-dependent pathways. J Biol Chem 2004;279:25535-25543. [PubMed: 15054096]

24. Weinstein DM, Mihm MJ, Bauer JA. Cardiac peroxynitrite formation and left ventricular dysfunction following doxorubicin treatment in mice. J Pharmacol Exp Ther 2000;294:396-401. [PubMed: 10871338]

25. Mukhopadhyay P, Rajesh M, Batkai S, Kashiwaya Y, Hasko G, Liaudet L, Szabo C, Pacher P. Role of superoxide, nitric oxide, and peroxynitrite in doxorubicin-induced cell death in vivo and in vitro. Am J Physiol Heart Circ Physiol 2009;296:H1466-1483. [PubMed: 19286953]

26. Pacher P, Liaudet L, Bai P, Virag L, Mabley JG, Hasko G, Szabo C. Activation of poly(ADPribose) polymerase contributes to development of doxorubicin-induced heart failure. J Pharmacol Exp Ther 2002;300:862-867. [PubMed: 11861791]

27. Pacher P, Liaudet L, Bai P, Mabley JG, Kaminski PM, Virag L, Deb A, Szabo E, Ungvari Z, Wolin MS, Groves JT, Szabo C. Potent metalloporphyrin peroxynitrite decomposition catalyst protects against the development of doxorubicin-induced cardiac dysfunction. Circulation 2003;107:896-904. [PubMed: 12591762]

28. Mukhopadhyay P, Batkai S, Rajesh M, Czifra N, Harvey-White J, Hasko G, Zsengeller Z, Gerard NP, Liaudet L, Kunos G, Pacher P. Pharmacological inhibition of CB1 cannabinoid receptor protects against doxorubicin-induced cardiotoxicity. J Am Coll Cardiol 2007;50:528-536. [PubMed: 17678736]

29. Chandran K, Aggarwal D, Migrino RQ, Joseph J, McAllister D, Konorev EA, Antholine WE, Zielonka J, Srinivasan S, Avadhani NG, Kalyanaraman B. Doxorubicin inactivates myocardial cytochrome c oxidase in rats: cardioprotection by Mito-Q. Biophys J 2009;96:1388-1398. [PubMed: 19217856]

30. Doroshow JH, Davies KJ. Redox cycling of anthracyclines by cardiac mitochondria. II. Formation of superoxide anion, hydrogen peroxide, and hydroxyl radical. J Biol Chem 1986;261:3068-3074. [PubMed: 3005279]

31. Pacher P, Batkai S, Osei-Hyiaman D, Offertaler L, Liu J, Harvey-White J, Brassai A, Jarai Z, Cravatt BF, Kunos G. Hemodynamic profile, responsiveness to anandamide, and baroreflex 
sensitivity of mice lacking fatty acid amide hydrolase. Am J Physiol Heart Circ Physiol 2005;289:H533-541. [PubMed: 15821037]

32. Pacher P, Nagayama T, Mukhopadhyay P, Batkai S, Kass DA. Measurement of cardiac function using pressure-volume conductance catheter technique in mice and rats. Nat Protoc 2008;3:14221434. [PubMed: 18772869]

33. Forman HJ. Reactive oxygen species and alpha, beta-unsaturated aldehydes as second messengers in signal transduction. Ann N Y Acad Sci 1203:35-44. [PubMed: 20716281]

34. Forman HJ, Dickinson DA. Introduction to serial reviews on 4-hydroxy-2-nonenal as a signaling molecule. Free Radic Biol Med 2004;37:594-596. [PubMed: 15288117]

35. Forman HJ, Fukuto JM, Miller T, Zhang H, Rinna A, Levy S. The chemistry of cell signaling by reactive oxygen and nitrogen species and 4-hydroxynonenal. Arch Biochem Biophys 2008;477:183-195. [PubMed: 18602883]

36. Levine RL. Carbonyl modified proteins in cellular regulation, aging, and disease. Free Radic Biol Med 2002;32:790-796. [PubMed: 11978480]

37. Eiserich JP, Hristova M, Cross CE, Jones AD, Freeman BA, Halliwell B, van der Vliet A. Formation of nitric oxide-derived inflammatory oxidants by myeloperoxidase in neutrophils. Nature 1998;391:393-397. [PubMed: 9450756]

38. Baldus S, Eiserich JP, Brennan ML, Jackson RM, Alexander CB, Freeman BA. Spatial mapping of pulmonary and vascular nitrotyrosine reveals the pivotal role of myeloperoxidase as a catalyst for tyrosine nitration in inflammatory diseases. Free Radic Biol Med 2002;33:1010. [PubMed: 12361810]

39. Schopfer FJ, Baker PR, Freeman BA. NO-dependent protein nitration: a cell signaling event or an oxidative inflammatory response? Trends Biochem Sci 2003;28:646-654. [PubMed: 14659696]

40. Radi R. Nitric oxide, oxidants, and protein tyrosine nitration. Proceedings of the National Academy of Sciences of the United States of America 2004;101:4003-4008. [PubMed: 15020765]

41. Dikalov SI, Li W, Mehranpour P, Wang SS, Zafari AM. Production of extracellular superoxide by human lymphoblast cell lines: comparison of electron spin resonance techniques and cytochrome C reduction assay. Biochem Pharmacol 2007;73:972-980. [PubMed: 17222393]

42. Mariappan N, Elks CM, Fink B, Francis J. TNF-induced mitochondrial damage: a link between mitochondrial complex I activity and left ventricular dysfunction. Free Radic Biol Med 2009;46:462-470. [PubMed: 19041937]

43. Rothe G, Oser A, Valet G. Dihydrorhodamine 123: a new flow cytometric indicator for respiratory burst activity in neutrophil granulocytes. Naturwissenschaften 1988;75:354-355. [PubMed: 3211206]

44. Fearon DT, Collins LA. Increased expression of C3b receptors on polymorphonuclear leukocytes induced by chemotactic factors and by purification procedures. J Immunol 1983;130:370-375. [PubMed: 6847888]

45. Vowells SJ, Sekhsaria S, Malech HL, Shalit M, Fleisher TA. Flow cytometric analysis of the granulocyte respiratory burst: a comparison study of fluorescent probes. J Immunol Methods 1995;178:89-97. [PubMed: 7829869]

46. Mukhopadhyay P, Pan H, Rajesh M, Batkai S, Patel V, Harvey-White J, Mukhopadhyay B, Hasko G, Gao B, Mackie K, Pacher P. CB1 cannabinoid receptors promote oxidative/nitrosative stress, inflammation and cell death in a murine nephropathy model. Br J Pharmacol 2010;160:657-668. [PubMed: 20590569]

47. Pacher P, Batkai S, Kunos G. Haemodynamic profile and responsiveness to anandamide of TRPV1 receptor knock-out mice. J Physiol 2004;558:647-657. [PubMed: 15121805]

48. Gary-Bobo M, Elachouri G, Gallas JF, Janiak P, Marini P, Ravinet-Trillou C, Chabbert M, Cruccioli N, Pfersdorff C, Roque C, Arnone M, Croci T, Soubrie P, Oury-Donat F, Maffrand JP, Scatton B, Lacheretz F, Le Fur G, Herbert JM, Bensaid M. Rimonabant reduces obesity-associated hepatic steatosis and features of metabolic syndrome in obese Zucker fa/fa rats. Hepatology 2007;46:122-129. [PubMed: 17526015]

49. Pacher P, Hasko G. Endocannabinoids and cannabinoid receptors in ischaemia-reperfusion injury and preconditioning. Br J Pharmacol 2008;153:252-262. [PubMed: 18026124] 
50. Kadoi Y, Goto F. Effects of AM281, a cannabinoid antagonist, on circulatory deterioration and cytokine production in an endotoxin shock model: comparison with norepinephrine. J Anesthesia 2006;20:284-289.

51. Villanueva A, Yilmaz MS, Millington WR, Cutrera RA, Stouffer DG, Parsons LH, Cheer JF, Feleder C. Central cannabinoid-1 receptor antagonist administration prevents endotoxic hypotension affecting norepinephrine release in the preoptic anterior hypothalamic area. Shock 2009;32:614-620. [PubMed: 19295473]

52. Schafer A, Pfrang J, Neumuller J, Fiedler S, Ertl G, Bauersachs J. The cannabinoid receptor-1 antagonist rimonabant inhibits platelet activation and reduces pro-inflammatory chemokines and leukocytes in Zucker rats. Br J Pharmacol 2008;154:1047-1054. [PubMed: 18469848]

53. Malfitano AM, Laezza C, Pisanti S, Gazzerro P, Bifulco M. Rimonabant (SR141716) exerts antiproliferative and immunomodulatory effects in human peripheral blood mononuclear cells. Br J Pharmacol 2008;153:1003-1010. [PubMed: 18157162]

54. Myers CE, McGuire WP, Liss RH, Ifrim I, Grotzinger K, Young RC. Adriamycin: the role of lipid peroxidation in cardiac toxicity and tumor response. Science 1977;197:165-167. [PubMed: 877547]

55. Doroshow JH, Locker GY, Ifrim I, Myers CE. Prevention of doxorubicin cardiac toxicity in the mouse by N-acetylcysteine. J Clin Invest 1981;68:1053-1064. [PubMed: 7287901]

56. Konorev EA, Kennedy MC, Kalyanaraman B. Cell-permeable superoxide dismutase and glutathione peroxidase mimetics afford superior protection against doxorubicin-induced cardiotoxicity: the role of reactive oxygen and nitrogen intermediates. Arch Biochem Biophys 1999;368:421-428. [PubMed: 10441396]

57. Kalivendi SV, Konorev EA, Cunningham S, Vanamala SK, Kaji EH, Joseph J, Kalyanaraman B. Doxorubicin activates nuclear factor of activated T-lymphocytes and Fas ligand transcription: role of mitochondrial reactive oxygen species and calcium. Biochem J 2005;389:527-539. [PubMed: 15799720]

58. Zhu W, Zou Y, Aikawa R, Harada K, Kudoh S, Uozumi H, Hayashi D, Gu Y, Yamazaki T, Nagai R, Yazaki Y, Komuro I. MAPK superfamily plays an important role in daunomycin-induced apoptosis of cardiac myocytes. Circulation 1999;100:2100-2107. [PubMed: 10562267]

59. Singal PK, Iliskovic N. Doxorubicin-induced cardiomyopathy. N Engl J Med 1998;339:900-905. [PubMed: 9744975]

60. Ishii Y, Sakamoto T, Ito R, Yanaga K. F(2)-isoprostanes and 2-arachidonylglycerol as biomarkers of lipid peroxidation in pigs with hepatic ischemia/reperfusion injury. J Surg Res 2009;161:139145. [PubMed: 19439322]

61. Pacher P, Gao B. Endocannabinoids and liver disease. III. Endocannabinoid effects on immune cells: implications for inflammatory liver diseases. Am J Physiol Gastrointest Liver Physiol 2008;294:G850-854. [PubMed: 18239059]

62. Dalton GD, Bass CE, Van Horn C, Howlett AC. Signal transduction via cannabinoid receptors. CNS Neurol Disord Drug Targets 2009;8:422-31. [PubMed: 19839935]

63. Riad A, Bien S, Westermann D, Becher PM, Loya K, Landmesser U, Kroemer HK, Schultheiss HP, Tschope C. Pretreatment with statin attenuates the cardiotoxicity of Doxorubicin in mice. Cancer Res 2009;69:695-699. [PubMed: 19147586]

64. Davies KJ, Doroshow JH. Redox cycling of anthracyclines by cardiac mitochondria. I. Anthracycline radical formation by NADH dehydrogenase. J Biol Chem 1986;261:3060-3067. [PubMed: 3456345]

65. Pacher P, Beckman JS, Liaudet L. Nitric oxide and peroxynitrite in health and disease. Physiol Rev 2007;87:315-424. [PubMed: 17237348]

66. Szabo C, Ischiropoulos H, Radi R. Peroxynitrite: biochemistry, pathophysiology and development of therapeutics. Nat Rev Drug Discov 2007;6:662-680. [PubMed: 17667957]

67. Levrand S, Vannay-Bouchiche C, Pesse B, Pacher P, Feihl F, Waeber B, Liaudet L. Peroxynitrite is a major trigger of cardiomyocyte apoptosis in vitro and in vivo. Free Radic Biol Med 2006;41:886-895. [PubMed: 16934671] 
68. Obrosova IG. Peroxynitrite and cardiomyocyte cell death: an evolving story. A commentary on "Peroxynitrite is a major trigger of cardiomyocyte apoptosis in vitro and in vivo". Free Radic Biol Med 2006;41:866-868. [PubMed: 16934667]

69. Denicola A, Radi R. Peroxynitrite and drug-dependent toxicity. Toxicology 2005;208:273-288. [PubMed: 15691591]

70. Wang S, Kotamraju S, Konorev E, Kalivendi S, Joseph J, Kalyanaraman B. Activation of nuclear factor-kappaB during doxorubicin-induced apoptosis in endothelial cells and myocytes is proapoptotic: the role of hydrogen peroxide. Biochem J 2002;367:729-740. [PubMed: 12139490]

71. Pacher P, Szabo C. Role of the peroxynitrite-poly(ADP-ribose) polymerase pathway in human disease. Am J Pathol 2008;173:2-13. [PubMed: 18535182]

72. Liu J, Gao B, Mirshahi F, Sanyal AJ, Khanolkar AD, Makriyannis A, Kunos G. Functional CB1 cannabinoid receptors in human vascular endothelial cells. Biochem J 2000;346(Pt 3):835-840. [PubMed: 10698714]

73. Santoro A, Pisanti S, Grimaldi C, Izzo AA, Borrelli F, Proto MC, Malfitano AM, Gazzerro P, Laezza C, Bifulco M. Rimonabant inhibits human colon cancer cell growth and reduces the formation of precancerous lesions in the mouse colon. Int J Cancer 2009;125:996-1003. [PubMed: 19479993]

74. Kunos G, Osei-Hyiaman D, Batkai S, Sharkey KA, Makriyannis A. Should peripheral CB(1) cannabinoid receptors be selectively targeted for therapeutic gain? Trends Pharmacol Sci 2009;30:1-7. [PubMed: 19042036]

75. Tam J, Vemuri VK, Liu J, Batkai S, Mukhopadhyay B, Godlewski G, Osei-Hyiaman D, Ohnuma S, Ambudkar SV, Pickel J, Makriyannis A, Kunos G. Peripheral CB1 cannabinoid receptor blockade improves cardiometabolic risk in mouse models of obesity. J Clin Invest 120:2953-2966. [PubMed: 20664173] 


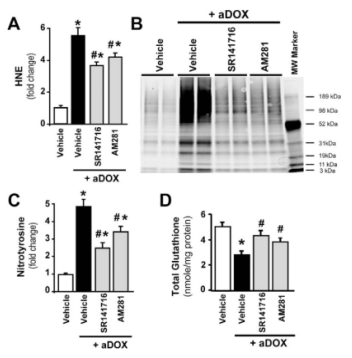

Figure 1. Cannabinoid $\mathrm{CB}_{1}$ receptor inhibition attenuates acute DOX-induced increased myocardial oxidative and nitrative stress and impaired antioxidant defense 5-day following DOX administration

Panel A: DOX administration enhanced myocardial HNE levels (marker of oxidative stress), which were attenuated by $\mathrm{CB}_{1}$ antagonists AM281 and SR141716. Panel B:

Immunoprecipitation for myocardial nitrotyrosine (NT; marker of nitrative stress) shows DOX-induced increased NT formation, which was attenuated by $\mathrm{CB}_{1}$ antagonists. Panel C: Experiments from quantitative NT ELISA demonstrate DOX-induced increased myocardial NT formation, which was attenuated by $\mathrm{CB}_{1}$ antagonists. Panel D: Measurements of myocardial glutathione content showed DOX-induced decreases, which was attenuated by $\mathrm{CB}_{1}$ antagonists. Results are mean \pm SEM of 4-7 experiments/group for panels $\mathrm{A}, \mathrm{C}$ and D. $* \mathrm{P}<0.05$ vs. vehicle; $\# \mathrm{P}<0.05$ vs. DOX treated mice. 


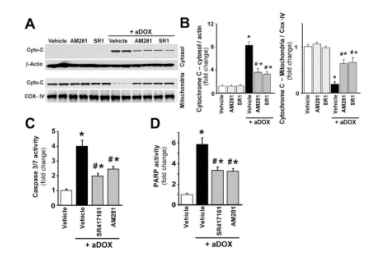

Figure 2. Cannabinoid $\mathrm{CB}_{1}$ receptor inhibition attenuates acute DOX-induced increased myocardial cytochrome $\mathrm{C}$ release and cell death 5-day following DOX administration Panel A: representative immunoblot from myocardium shows enhanced release of cytochrome $\mathrm{C}$ (Cyto-C) into the cytosol after DOX administration, which was attenuated with $\mathrm{CB}_{1}$ receptor antagonists $\mathrm{AM} 281$ and SR141716. Panel B: quantification of cytochrome $\mathrm{C}$ release (in the cytosol it is normalized to $\beta$-actin, in the mitochondria to COX-IV). Panels C and D: DOX administration enhanced myocardial Caspase 3/7 (Panel C) and PARP (Panel D) activities (markers of cell death), which were attenuated by $\mathrm{CB}_{1}$ antagonists AM281 and SR141716. Results are mean \pm SEM of 6-8 experiments/group. $* \mathrm{P}<0.05$ vs. vehicle; $\# \mathrm{P}<0.05$ vs. DOX treated mice. 

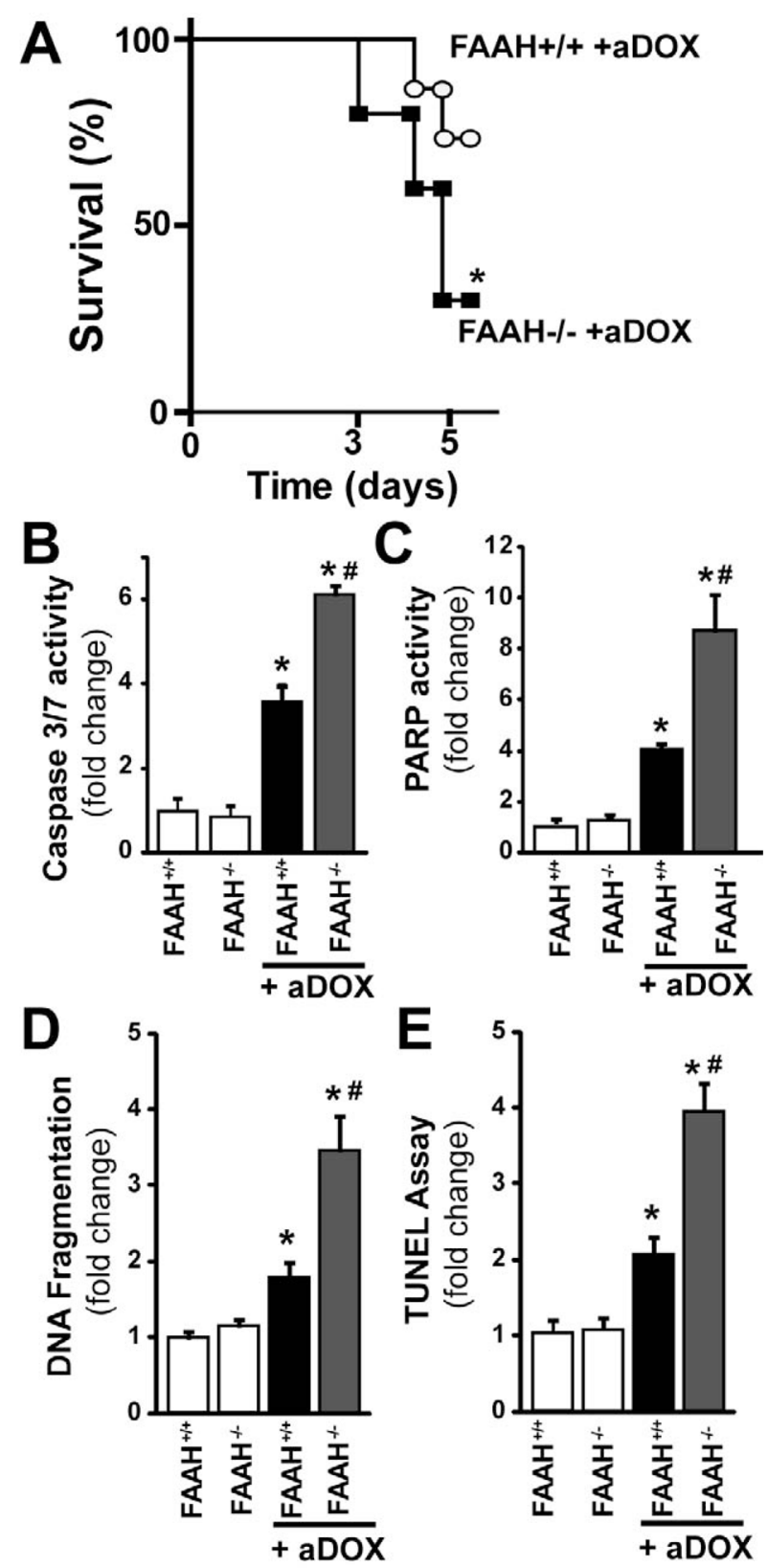

Figure 3. Genetic deletion of FAAH is associated with enhanced acute DOX-induced myocardial cell death 3-day following DOX administration and decreased survival thereafter Panel A: FAAH-/- mice treated with DOX show markedly reduced survival, compared to their wild type $(\mathrm{FAAH}+/+$ ) littermates ( $\mathrm{n}=11$ and 13/group). $\mathrm{P}<0.05$ vs. DOX-treated mice by Kaplan-Meier survival analysis. Panels B-D shows markedly increased myocardial cell death (both apoptotic and PARP-dependent) in FAAH-/- mice treated with DOX compared to their wild type $(\mathrm{FAAH}+/+)$ littermates. Results are mean \pm SEM of 6-8 experiments/group. $* \mathrm{P}<0.05$ vs. vehicle in $\mathrm{FAAH}+/+$ or $\mathrm{FAAH}-/-$ mice; $\# \mathrm{P}<0.05$ vs. DOX in FAAH $+/+$ treated mice. 


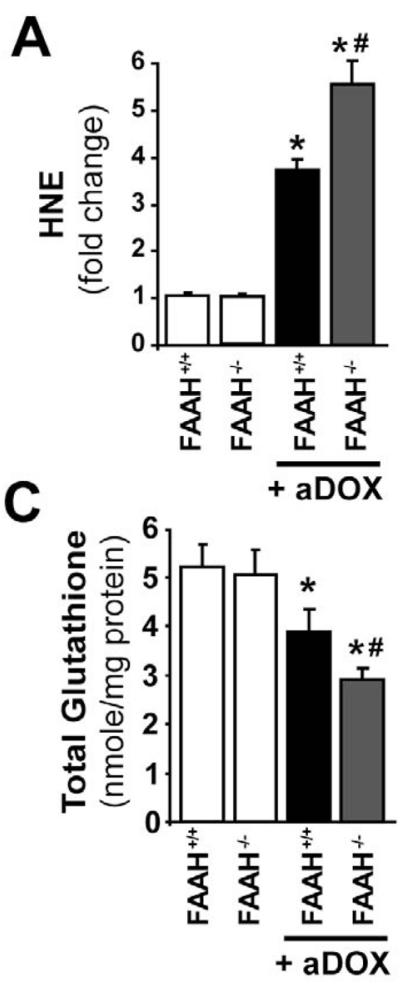

B

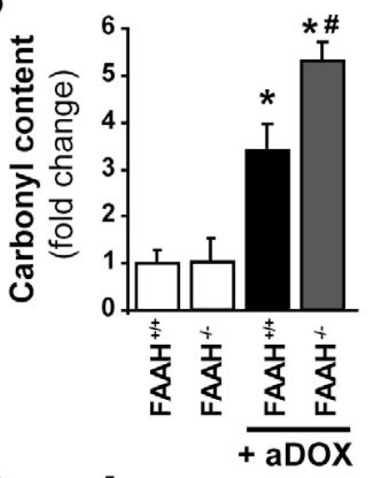

D

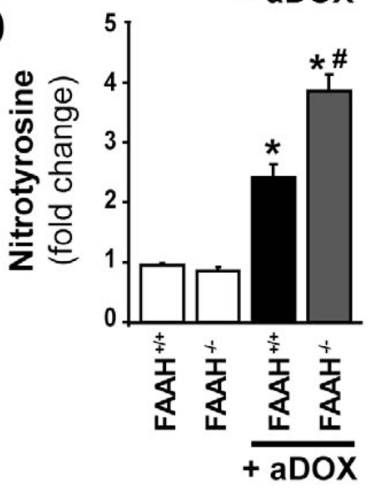

Figure 4. Genetic deletion of FAAH is associated with enhanced acute DOX-induced myocardial oxidative and nitrative stress 3-day following DOX administration

Panels A-D show that FAAH-/- mice treated with DOX had significantly increased oxidative and nitrative stress compared to their wild type (FAAH+/+) littermates. Results are mean \pm SEM of $5-8$ experiments/group. $* \mathrm{P}<0.05$ vs. vehicle in $\mathrm{FAAH}+/+$ or $\mathrm{FAAH}-/-$ mice; $\# \mathrm{P}<0.05$ vs. DOX in FAAH+/+ treated mice. 

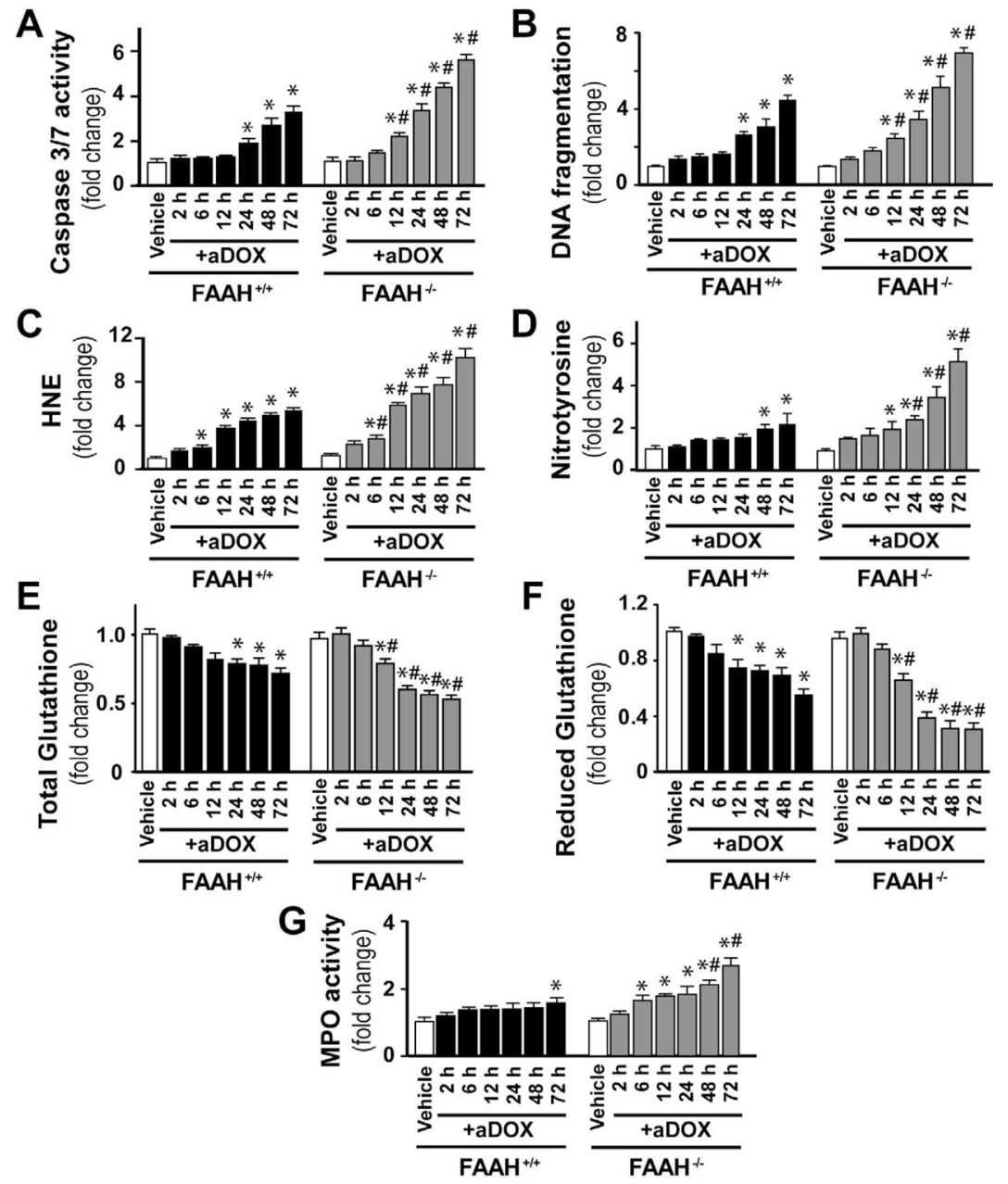

Figure 5. Genetic deletion of FAAH is associated with time-dependently enhanced DOX-induced cell death, oxidative and nitrative stress

Panel A-G show time-dependent increase of DOX-induced myocardial cell death, oxidative and nitrative stress, neutrophil infiltration (MPO activity) and decrease in reduced as well as total glutathione contents. These changes were aggravated in the absence of FAAH. Results are mean \pm SEM of $16-36$ experiments/group. $* \mathrm{P}<0.05$ vs. vehicle in $\mathrm{FAAH}+/+$ or $\mathrm{FAAH}-/$ - mice; \#P<0.05 vs. DOX in FAAH+/+ treated mice. 


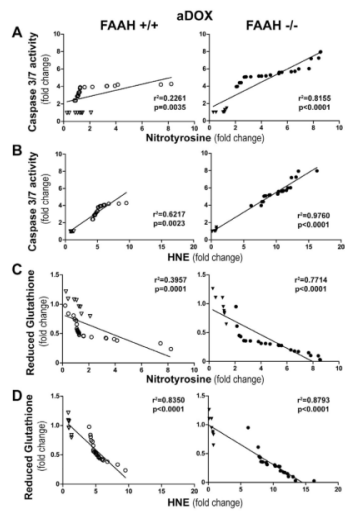

Figure 6. Myocardial oxidative and nitrative stress markers show direct positive correlation with cell death marker and negative correlation with reduced glutathione content 3 days following the administration of an acute single dose of DOX in FAAH+/+ and FAAH-/- mice

Panel A-B show direct correlation of nitrotyrosine and HNE protein adducts with caspase 3/7 activity in FAAH+/+ and FAAH-/- mice. Panel C-D show inverse correlation of reduced glutathione with nitrotyrosine and HNE protein adducts in FAAH+/+ and FAAH-/ - mice. Results are mean \pm SEM of 8-24 experiments/group. Hollow triangles and circles denote data points from FAAH+/+ mice without and with DOX (left), respectively, while filled triangles and circles indicate data points from FAAH $-/-$ mice without and with DOX (right), respectively. 

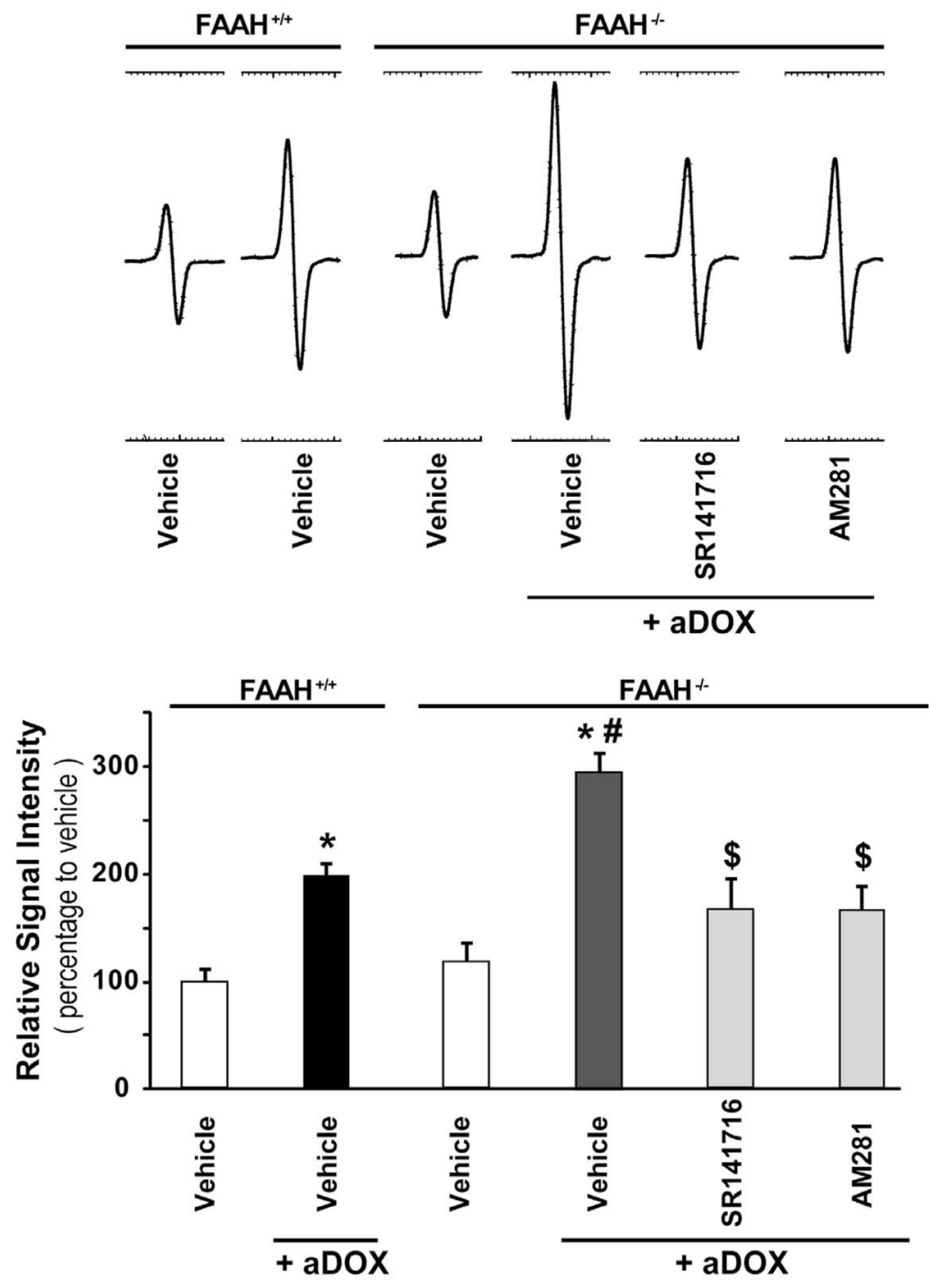

Figure 7. The enhanced acute DOX-induced myocardial ROS generation in FAAH-I- mice is attenuated by $\mathrm{CB}_{1}$ antagonists

Upper representative EPR traces show markedly increased DOX-induced myocardial ROS generation in FAAH-/- mice compared to FAAH+/+ mice 3 days following DOX administration, which is attenuated by $\mathrm{CB}_{1}$ antagonists SR141716 and AM281. Below panel shows quantifications. Results are mean \pm SEM of 4-5 experiments/group. $* \mathrm{P}<0.05$ vs. vehicle in $\mathrm{FAAH}+/+$ or FAAH $-/-$ mice; $\# \mathrm{P}<0.05$ vs. DOX in FAAH+/+ treated mice; $\$<0.05$ vs. DOX in FAAH $-/-$ treated mice. 

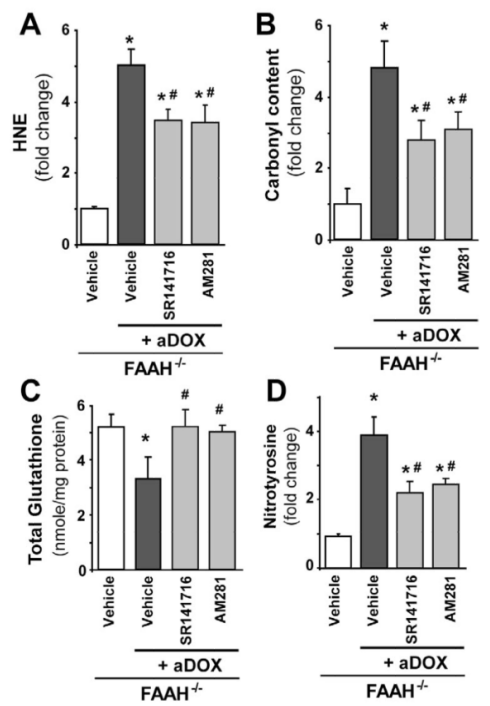

Figure 8. The enhanced acute DOX-induced myocardial oxidative/nitrative stress in FAAH-/mice is attenuated by $\mathrm{CB}_{1}$ antagonists

Panels A-D show markedly increased DOX-induced myocardial oxidative (HNE, protein carbonyl) and nitrative (nitrotyrosine) stress in FAAH-/- mice compared to FAAH+/+ littermates 3 days following DOX administration, which is attenuated by $\mathrm{CB}_{1}$ antagonists SR141716 and AM281. Results are mean \pm SEM of 5-7 experiments/group. $* \mathrm{P}<0.05$ vs. vehicle in FAAH $-/-$ mice; $\# \mathrm{P}<0.05$ vs. DOX in FAAH $-/-$ mice. 
A

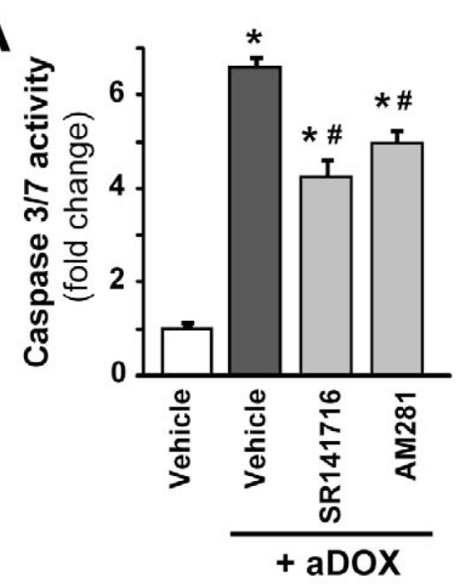

FAAH $^{-1-}$

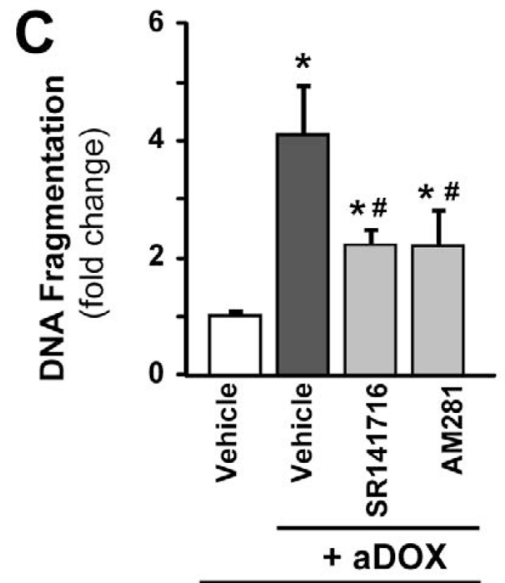

FAAH $^{-1-}$
B

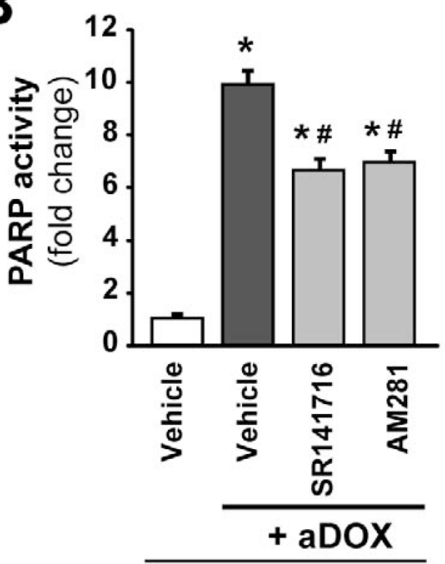

FAAH $^{-1-}$

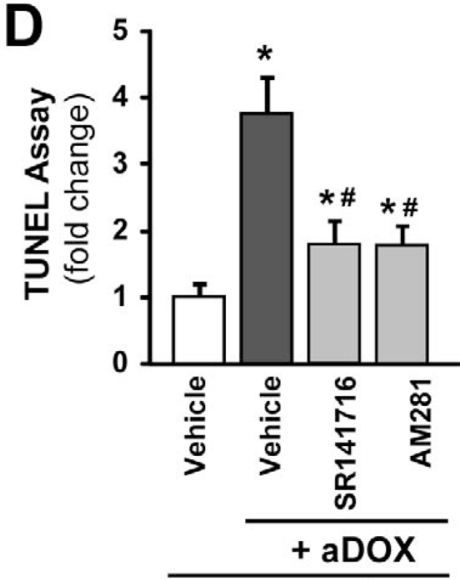

FAAH $^{-1-}$

Figure 9. The enhanced acute DOX-induced myocardial cell death in FAAH-/- mice is attenuated by $\mathrm{CB}_{1}$ antagonists

Panels A-D show markedly increased DOX-induced myocardial cell death in FAAH-Imice compared to FAAH+/+ littermates 3 days following DOX administration, which is attenuated by $\mathrm{CB}_{1}$ antagonists SR141716 and AM281. Results are mean \pm SEM of 5-8 experiments/group. * $\mathrm{P}<0.05$ vs. vehicle in FAAH $-/-$ mice; \# $<0.05$ vs. DOX in FAAH $-/-$ mice. 

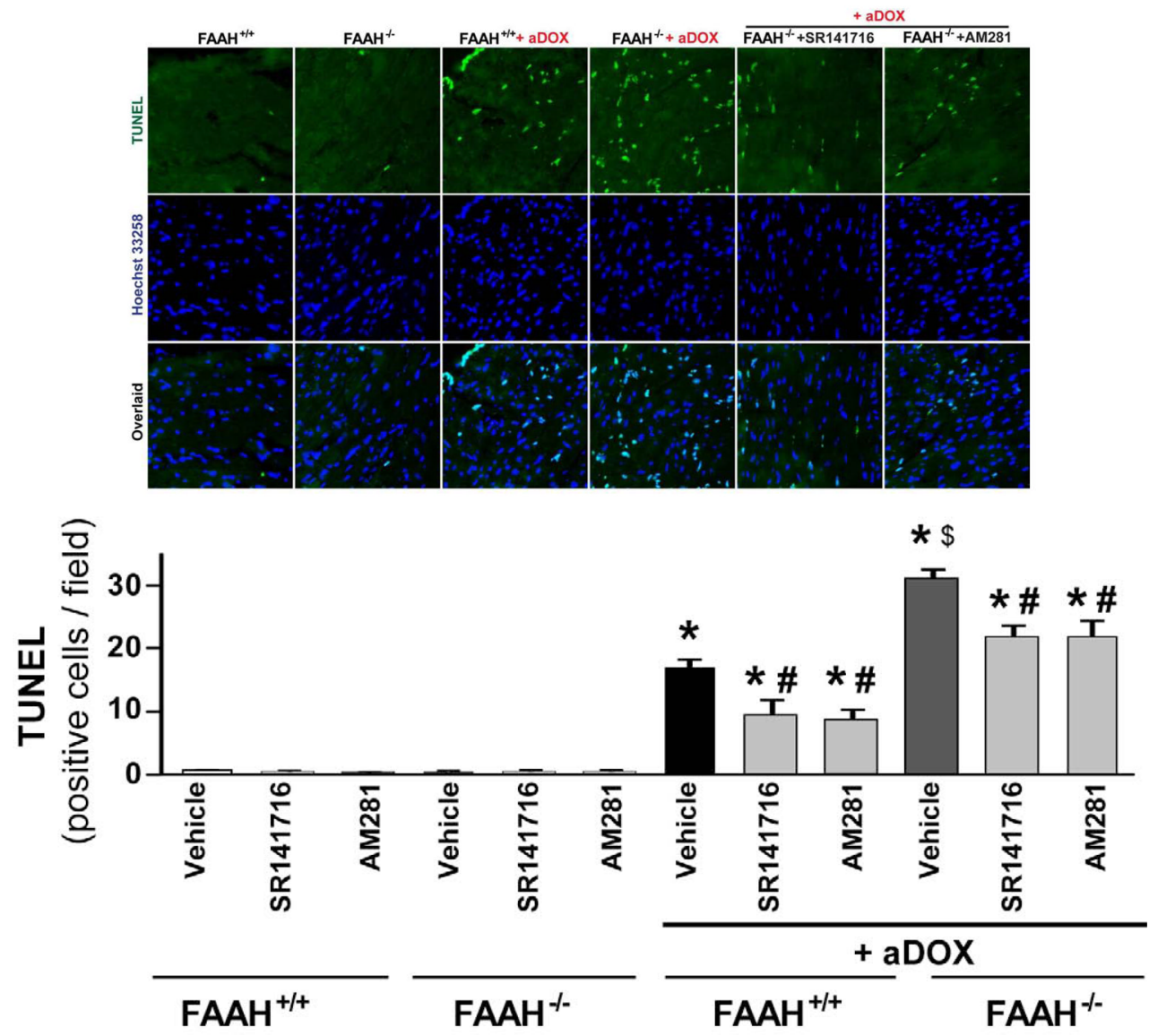

Figure 10. The enhanced acute DOX-induced myocardial apoptosis in FAAH-/- mice is attenuated by $\mathrm{CB}_{1}$ antagonists

Panels A: the upper row of images (green) shows representative TUNEL staining 3 days following DOX administration, the middle row (dark blue) is the nuclear staining, while the bottom one is the colocalization of both (light blue/white nuclei represents TUNEL positive cells). Panel B: quantification of myocardial TUNEL staining. Results are mean \pm SEM of 10-12 frames/group from 3-4 different hears. * $\mathrm{P}<0.05$ vs. vehicle in FAAH $-/-$ or FAAH+/ + mice; \#P<0.05 vs. DOX in FAAH+/+ or FAAH-/- mice; $\$ \mathrm{P}<0.05$ vs. DOX in FAAH+/+ mice. 

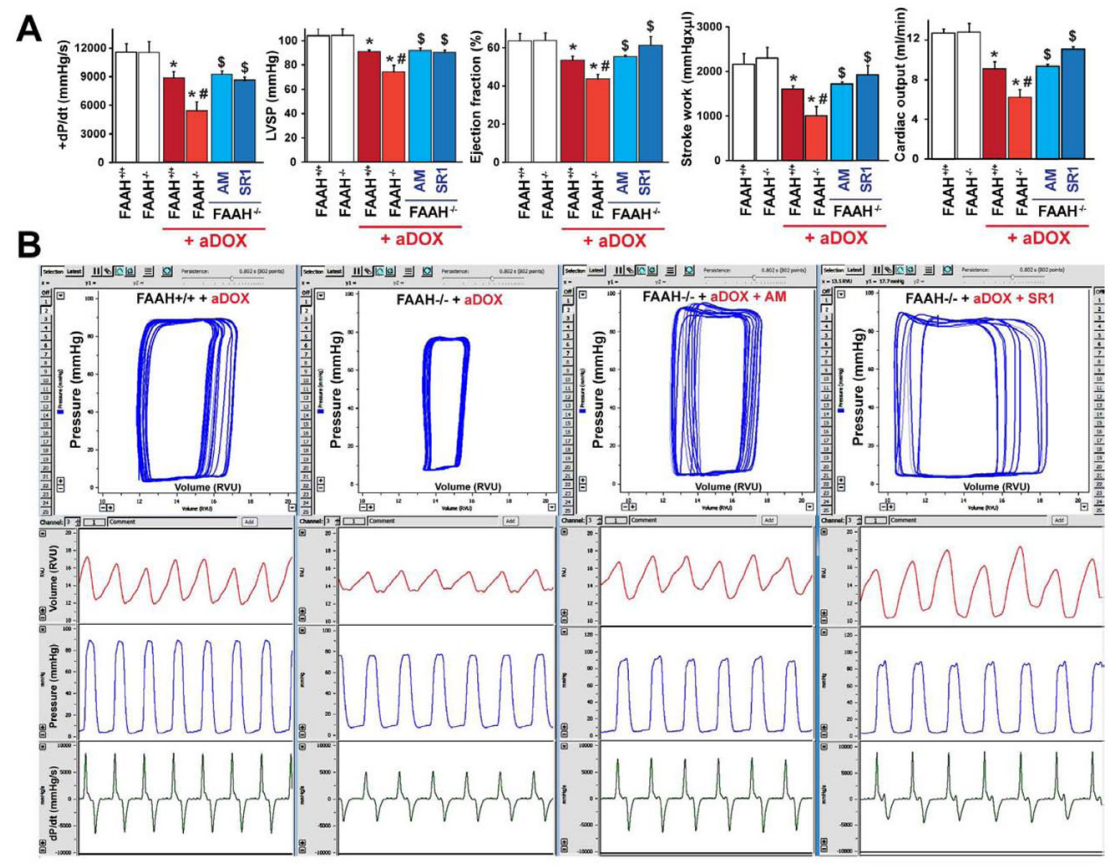

Figure 11. FAAH-/- mice develop more severe acute DOX-induced cardiac dysfunction Panel A shows decrease in markers of left ventricular contractile function (maximum first derivative of ventricular pressure with respect to time $(+\mathrm{dP} / \mathrm{dt})$, maximal left ventricular pressure (LVP), ejection fraction, stroke work and cardiac output) in FAAH+/+ and FAAH $-/-$ mice 3 days following acute DOX treatment (aDOX). The DOX-induced myocardial dysfunction was significantly more pronounced in FAAH-/- mice compared to their wildtype littermates (Figure 11A-B) and was improved by $\mathrm{CB}_{1}$ antagonists SR141716 (SR1) or AM281 (AM) treatment (Figure 11A-B). Results are mean \pm SEM of 5-7 experiments/group. $* \mathrm{P}<0.05$ vs. vehicle in $\mathrm{FAAH}+/+$ or $\mathrm{FAAH}-/-$ mice; $\# \mathrm{P}<0.05$ vs. DOX in $\mathrm{FAAH}+/+$ mice; $\$ \mathrm{P}<0.05$ vs. DOX in FAAH $-/-$ mice.

Panel B shows representative pressure-volume (P-V) loops (upper row, blue), volume signal (second row, red), left ventricular (LV) pressure signal (third row, blue) and derivative of the $\mathrm{LV}$ pressure signal (bottom row, green) in FAAH+/+ and FAAH-/- mice 3 days following acute DOX administration, and in FAAH $-/-$ mice treated with DOX with CB1 antagonists. Please note that the rightward shift of the $\mathrm{P}-\mathrm{V}$ loops, decrease in stroke volume and in the LV pressure signal amplitude and maximum first derivative of LV pressure with respect to time $(+\mathrm{dP} / \mathrm{dt})$ indicates depressed myocardial contractile performance. 

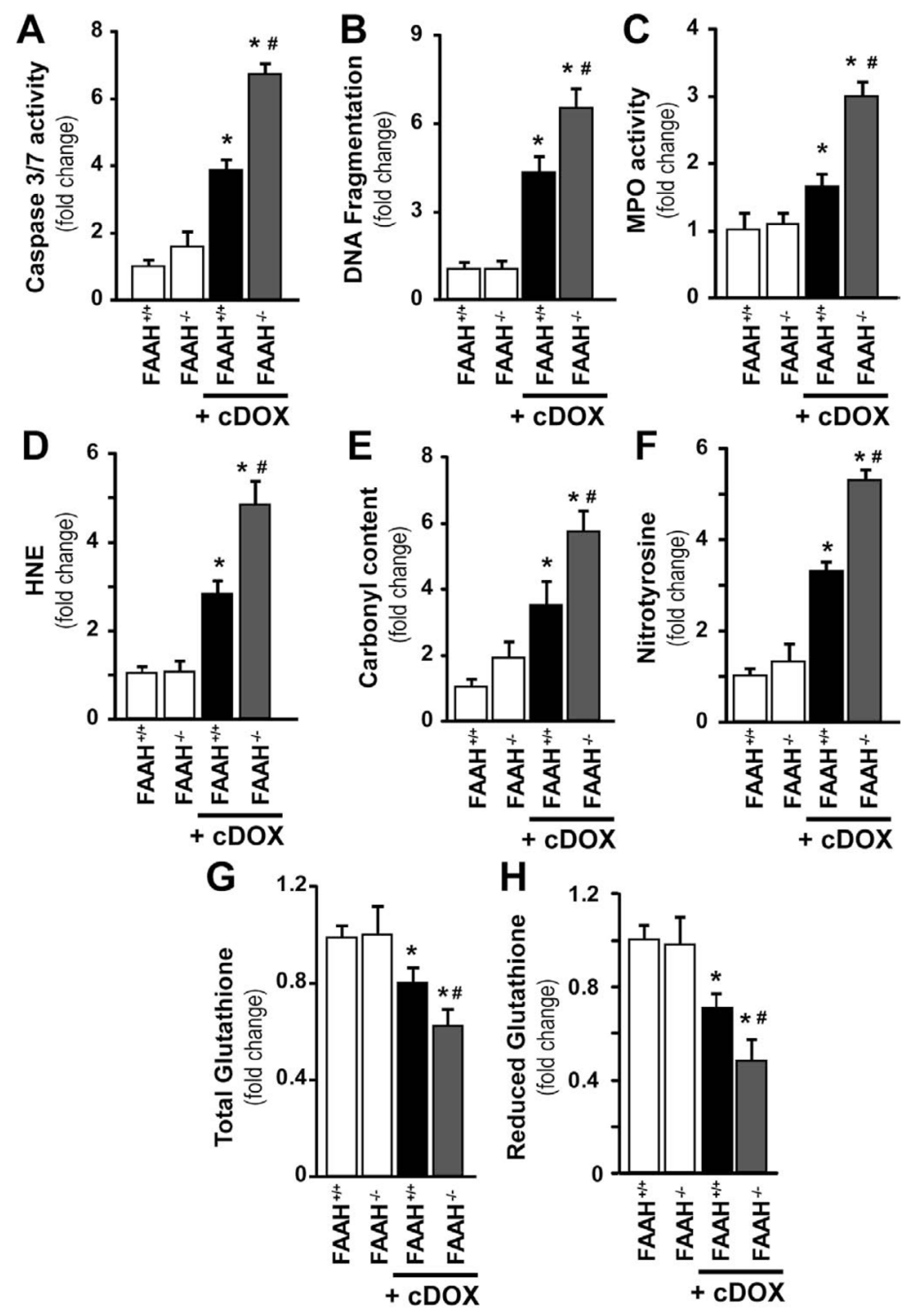

Figure 12. Enhanced chronic DOX-induced myocardial cell death, inflammation, and oxidative and nitrative stress in FAAH-/- mice

FAAH-/- mice treated with multiple low doses of DOX had markedly increased myocardial cell death (Panel A-B), neutrophil infiltration (Panel C; MPO activity) and significantly increased oxidative and nitrative stress (Panel D-H) compared to their wild type $(\mathrm{FAAH}+/+)$ littermates 30 days following the first DOX administration. Results are mean \pm SEM of $8-12$ experiments/group. $* \mathrm{P}<0.05$ vs. vehicle in $\mathrm{FAAH}+/+$ or $\mathrm{FAAH}-/-$ mice; $\# \mathrm{P}<0.05$ vs. DOX in FAAH $+/+$ treated mice. 


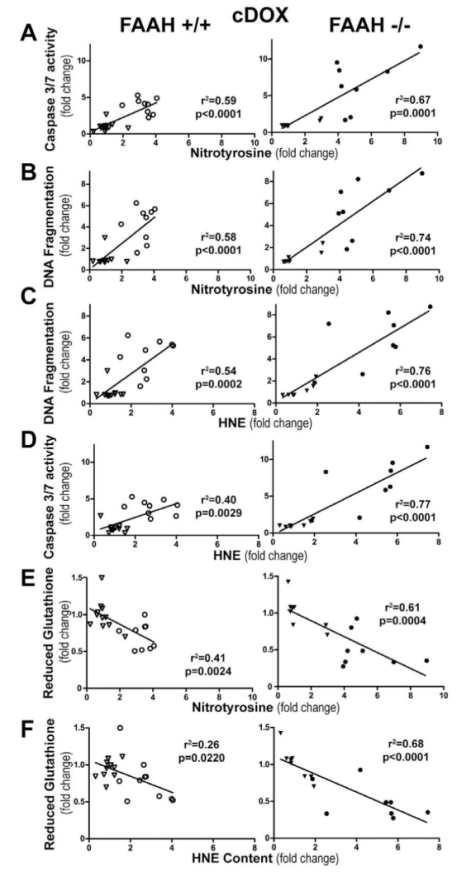

Figure 13. Myocardial oxidative and nitrative stress markers show direct correlation with cell death and reduced glutathione content after chronic DOX administration Panels A-D show direct correlation of myocardial nitrotyrosine and HNE with DNA fragmentation and caspase $3 / 7$ activity in FAAH+/+ and FAAH $-/-$ mice. Panels E-F show inverse correlation of reduced myocardial glutathione content with nitrotyrosine and HNE protein adduct content in FAAH+/+ (open) and FAAH-/- mice (solid) after vehicle (triangle) and DOX (circle) treatment. Results are mean \pm SEM of 8 experiments/group. 


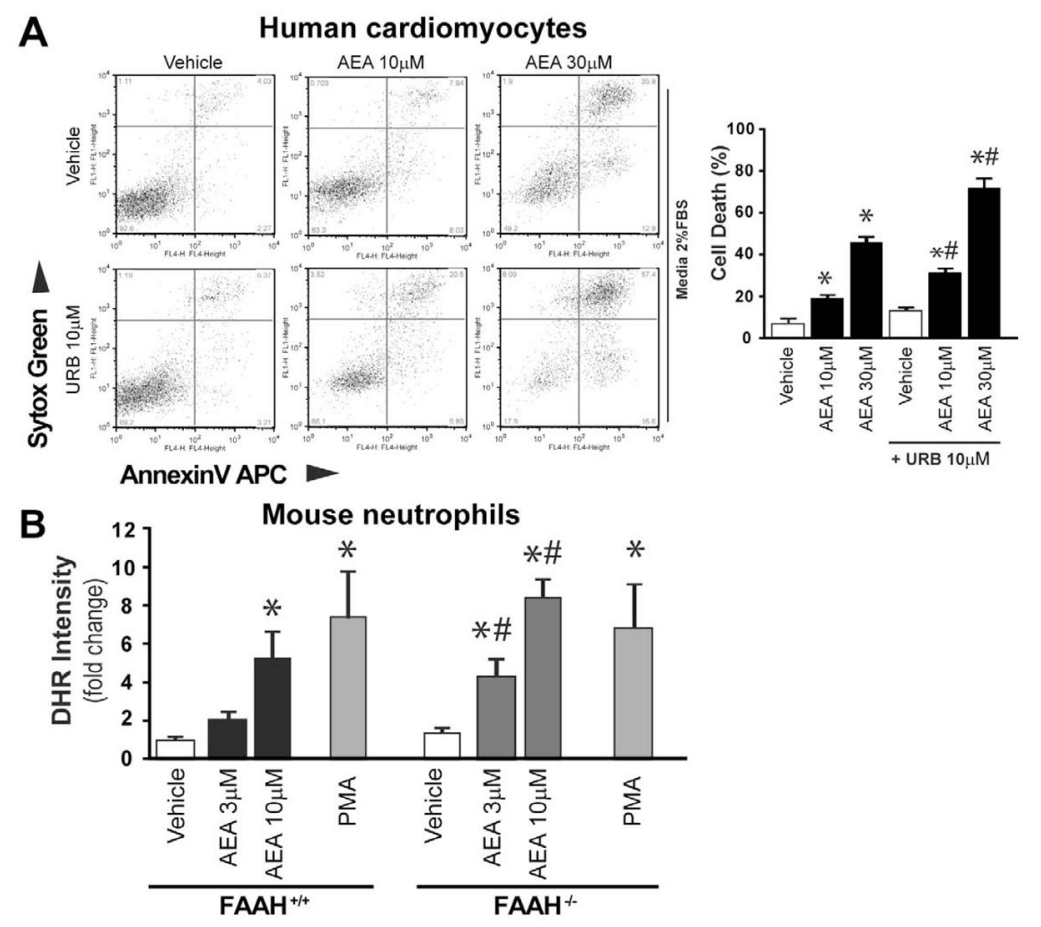

Figure 14. Anandamide enhances cell death in human cardiomyocytes treated with FAAH inhibitor, and increased ROS production in FAAH knockout neutrophils

Panel A shows that anandamide (AEA) enhances concentration-dependent cell death in human primary cardiomyocytes, which is more pronounced in the presence of FAAH inhibitor URB527. Panel B shows the dose concentration-dependent effect of anandamide (AEA) on respiratory burst in neutrophil granulocytes isolated from FAAH+/+ and FAAH-/ - mice. Phorbol Ester (PA) was used as positive control. 